WSRC-TR-99-00377, Revision 0

ITS Activity No. ITS-99-0101

\title{
COMPARISON OF DOW CORNING 544 ANTIFOAM TO IIT747 ANTIFOAM IN THE 1/240 SRAT (U)
}

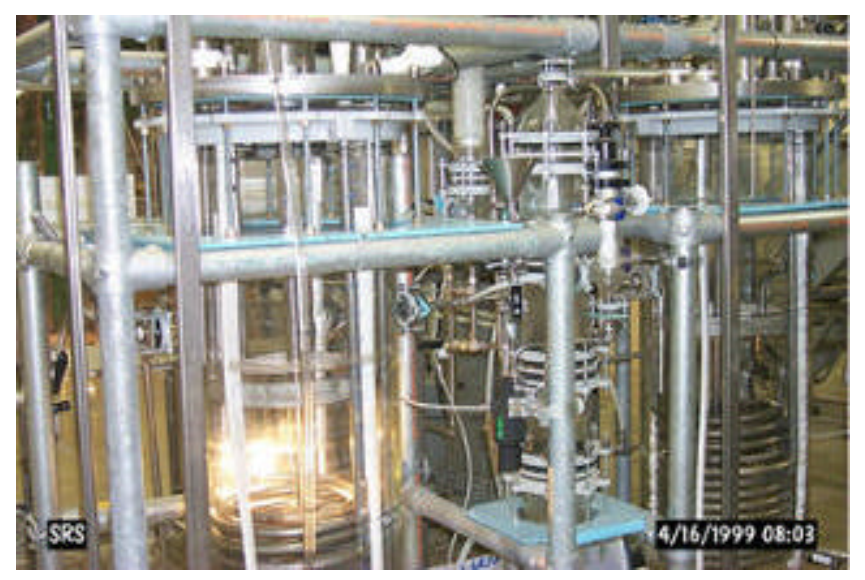

D. C. Koopman

Westinghouse Savannah River Company

Savannah River Site

Aiken, SC 29808

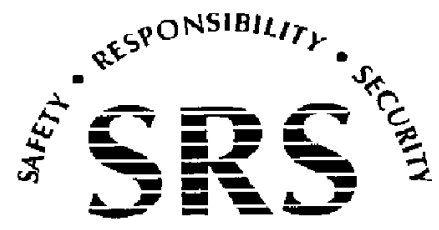

PREPARED FOR THE U.S. DEPARTMENT OF ENERGY UNDER CONTRACT NO. DE-AC09-96SR18500 
WSRC-TR-99-00377, Revision 0

ITS Activity No. ITS-99-0101

February 23, 2000

\section{DISCLAIMER}

This report was prepared as an account of work sponsored by an agency of the United States Government. Neither the United States Government nor any agency thereof, nor any of their employees, makes any warranty, express or implied, or assumes any legal liability or responsibility for the accuracy, completeness, or usefulness of any information, apparatus, product or process disclosed, or represents that its use would not infringe privately owned rights. Reference herein to any specific commercial product, process or service by trade name, trademark, manufacturer, or otherwise does not necessarily constitute or imply its endorsement, recommendation, or favoring by the United States Government or any agency thereof. The views and opinions of authors expressed herein do not necessarily state or reflect those of the United States Government or any agency thereof.

This report has been reproduced directly from the best available copy.

Available for sale to the public, in paper, from: U.S. Department of Commerce, National Technical Information Service, 5285 Port Royal Road, Springfield, VA 22161, phone: (800) 553-6847, fax: (703) 605-6900, email: orders@ntis.fedworld.gov online ordering: http://www.ntis.gov/ordering.htm

Available electronically at http://www.doe.gov/bridge

Available for a processing fee to U.S. Department of Energy and its contractors, in paper, from: U.S. Department of Energy, Office of Scientific and Technical Information, P.O. Box 62, Oak Ridge, TN 37831-0062, phone: (865 ) 576-8401, fax: (865) 5765728, email: reports@adonis.osti.gov 
WSRC-TR-99-00377, Revision 0 ITS Activity No. ITS-99-0101

February 23, 2000 
WSRC-TR-99-00377, Revision 0

ITS Activity No. ITS-99-0101

February 23, 2000

Keywords: DWPF, GFPS, SRAT, SME, Sludge, Tank 42, Antifoam, IIT, Dow Corning

Retention: Permanent

\title{
COMPARISON OF DOW CORNING 544 ANTIFOAM TO IIT747 ANTIFOAM IN THE 1/240 SRAT (U)
}

\author{
D. C. Koopman
}

Publication Date: December 17, 1999

Westinghouse Savannah River Company

Savannah River Site

Aiken, SC 29808

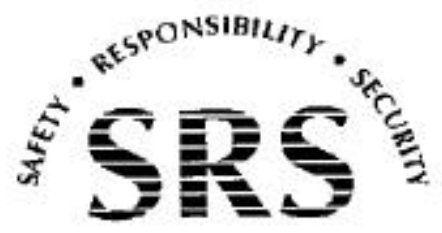

PREPARED FOR THE U.S. DEPARTMENT OF ENERGY UNDER CONTRACT NO. DE-AC09-96SR18500 
WSRC-TR-99-00377, Revision 0

ITS Activity No. ITS-99-0101

February 23, 2000

\section{APPROVALS}

D. C. Koopman, Author

Date

R. E. Eibling, Technical Reviewer

Date

L. F. Landon, Manager

Date 
WSRC-TR-99-00377, Revision 0

ITS Activity No. ITS-99-0101

February 23, 2000

\section{EXECUTIVE SUMMARY}

The Defense Waste Processing Facility requested that the Immobilization Technology Section determine if IIT747 antifoam is suitable for use in DWPF. IIT747 is a new antifoam developed at the Illinois Institute of Technology. HLW-DWPF-TTR-99-0012 ${ }^{1}$ also requested that ITS compare the relative effectiveness of IIT747 to Dow Corning 544 antifoam, develop an antifoam addition strategy to minimize foam present during DWPF SRAT and SME processing, and compare hydrogen production, nitrous oxide generation, and foam stability in duplicate experiments varying only the antifoam used. The TTR indicated that bench scale testing might be required to develop the optimum antifoam addition strategy. A task plan was written and approved $^{2}$.

Experiments were performed in the Glass Feed Preparation System (GFPS), a $1 / 240^{\text {th }}$ scale mockup of the DWPF Chemical Process Cell. Testing consisted of two sludge-only runs using a non-radioactive simulant of Tank 42 feed. The first run used Dow Corning 544 antifoam. The second run used IIT747 antifoam. Processing occurred for about eleven hours per day. The antifoam addition strategy was similar to that used in DWPF, but was adapted for days-only experimentation. Testing took place over a range of boil-up rates.

Major conclusions from the testing are:

- IIT747 antifoam was superior overall to Dow Corning 544 antifoam in controlling foam height and eliminating existing foams in these tests.

- Fresh Dow Corning 544 antifoam was ineffective at controlling foaming when the SRAT was first brought to boiling at $65-107 \%$ of the design basis DWPF boil-up flux ( $\left.45 \mathrm{lb} / \mathrm{hr} / \mathrm{ft}^{2}\right)$. The GFPS SRAT would have foamed over into the SRAT condenser if the steam flux had been increased above $60 \%$ of the design basis. Fresh IIT747 antifoam, however, was effective at controlling foaming when the SRAT was first brought to boiling at up to $107 \%$ of the maximum DWPF boil-up flux. Just over four inches of foam were observed, see Table I below.

Table I. Average SRAT Foam Heights At Initial Boiling Test

\begin{tabular}{|l|c|c|c|c|}
\hline \% Maximum DWPF flux: & $27 \%$ & $45 \%$ & $61 \%$ & $107 \%$ \\
\hline Dow Corning 544 Antifoam & 3.2 in. & 9.3 in. & 9.6 to $>17.6$ in. & $>17.6$ in. \\
\hline IIT747 Antifoam & 1.1 in. & 0.9 in. & 2.5 in. & 4.3 in. \\
\hline
\end{tabular}

\footnotetext{
${ }^{1}$ Determine Effectiveness of IIT747 Antifoam for use in DWPF, December 7, 1998, TTR Number: HLW-DWPFTTR-99-0012.

${ }^{2}$ D. P. Lambert and D. C. Koopman, Comparison of Dow Corning 544 Antifoam to IIT747 Antifoam in the 1/240 SRAT, April 23, 1999, WSRC-RP-99-00205.
} 
WSRC-TR-99-00377, Revision 0

ITS Activity No. ITS-99-0101

February 23, 2000

- The two antifoams were effective at controlling foaming in the middle and latter parts of the SRAT cycle and were roughly comparable. Dynamically stable foams of 1-12 inches in height were observed at $27-107 \%$ of the design basis DWPF boil-up flux. These foams collapsed when the steam supply was turned off.

- Both antifoams were effective at controlling foaming during the SME cycle. Dynamically stable foams of only 1-4 inches in depth were observed at boil-up fluxes of 26-107\% of the design basis DWPF boil-up flux.

- Adding IIT747 antifoam to a system already foaming uncontrollably eliminated the excess foam above the dynamically stable foam, i.e. it was an excellent defoamer.

- There was some evidence that IIT747 antifoam was beginning to lose its effectiveness after about eight hours of SRAT cycle processing. It remained effective for ten hours at which point the process was shut down. IIT747 antifoam lost its effectiveness during another 15 hour period, much of which was not at elevated temperature. An "every twelve hours" addition strategy at $100 \mathrm{ppm}$ may be inadequate in DWPF.

- Both antifoams are blends of several compounds containing carbon, hydrogen, oxygen, and/or silicon. The impact of either antifoam per $100 \mathrm{ppm}$ addition is an increase of about $0.0002 \%$ on the total silicon in the melter feed. Consequently, an antifoam switch is expected to have a negligible impact on glass chemistry.

\section{Recommendations for Future Work:}

1. DWPF should begin preparing to switch to IIT747 antifoam subject to completing item 2 below.

2. Tests should be made to refine the addition strategy for a $100 \mathrm{ppm}$ charge of IIT747 antifoam (suggest every eight hours if this testing can not be completed).

3. Tests should be performed with irradiated IIT747 antifoam to see it if retains its effectiveness. IIT747 antifoam could be used in the next shielded cell run.

4. Additional tests to determine the optimum antifoam addition concentration, the eventual fate of IIT747 antifoam components or decomposition products during processing, and any correlation between slurry rheology and foaminess should be performed.

5. The foaming issue should be revisited once a Salt Disposition Alternative decision has been made. This work did not investigate the effect of organics, etc. on foam heights. 
WSRC-TR-99-00377, Revision 0

ITS Activity No. ITS-99-0101

February 23, 2000

TABLE OF CONTENTS

EXECUTIVE SUMMARY ................................................................................................................

TABLE OF CONTENTS................................................................................................................viii

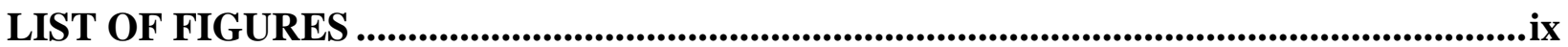

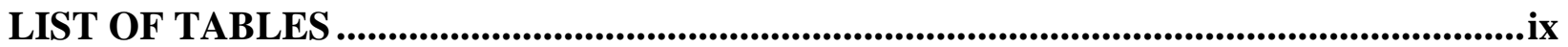

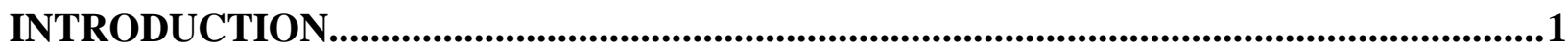

BACKGROUND .........................................................................................................................

DISCUSSION................................................................................................................................4

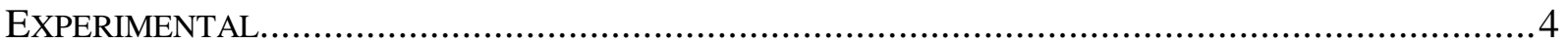

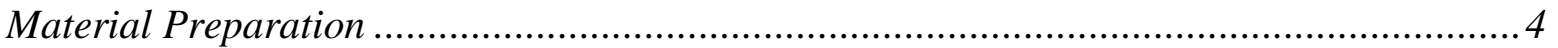

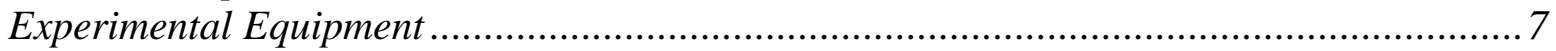

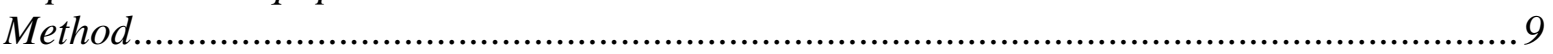

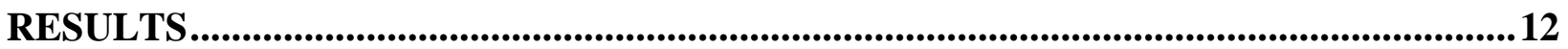

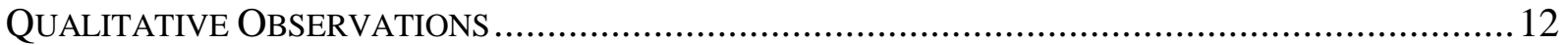

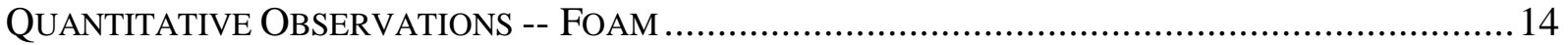

SRAT Foam Test \#1 .......................................................................................... 15

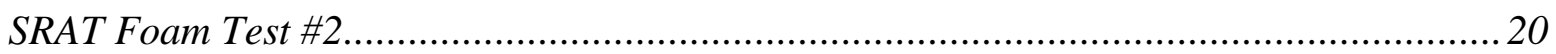

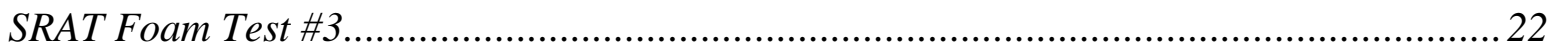

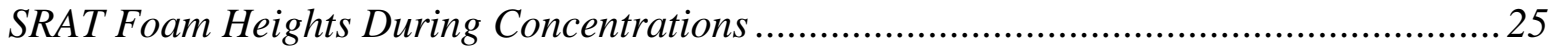

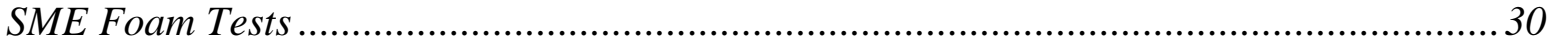

QuANTITATIVE OBSERVATIONS -- SRAT/SME CHEMISTRY DURING ANTIFOAM TESTING ........32

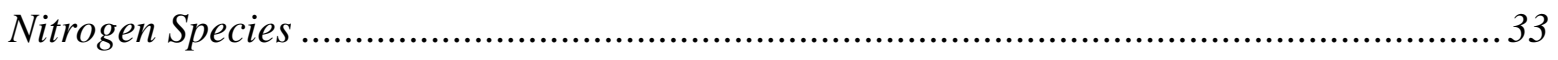

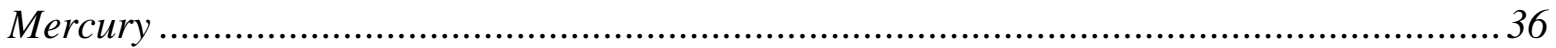

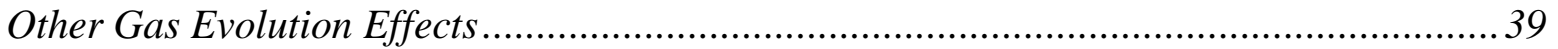

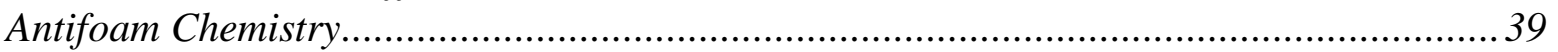

SUGGESTIONS FOR IMPROVING THE EXPERIMENT ...................................................... 41

CONCLUSIONS AND RECOMMENDATIONS...............................................................41

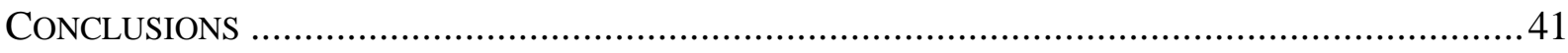

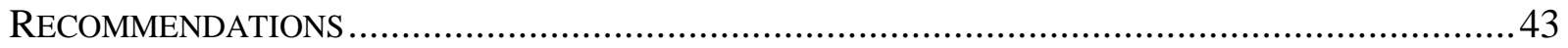

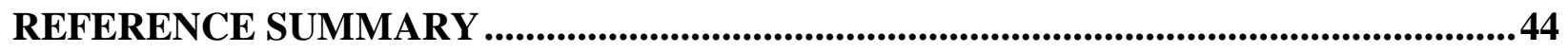

ACKNOWLEDGEMENTS ......................................................................................................46 
WSRC-TR-99-00377, Revision 0

ITS Activity No. ITS-99-0101

February 23, 2000

\section{LIST OF FIGURES}

Figure 1. Schematic of the Glass Feed Preparation System................................................... 8

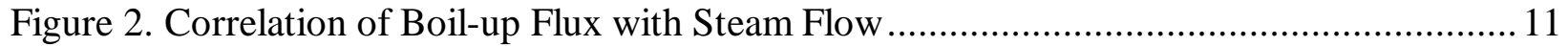

Figure 3. SRAT Foam at 27\% of DWPF Maximum Boil-up Flux.......................................... 16

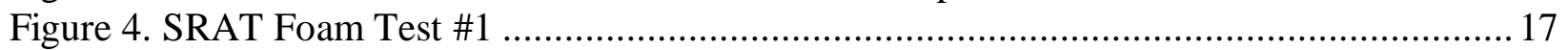

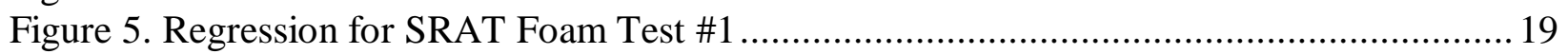

Figure 6. Foam in DC544-1C at 27\% DWPF Maximum Boil-up Flux......................................2 20

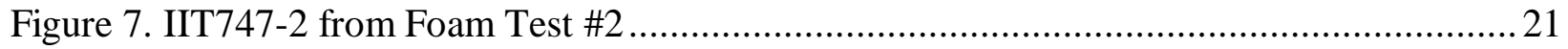

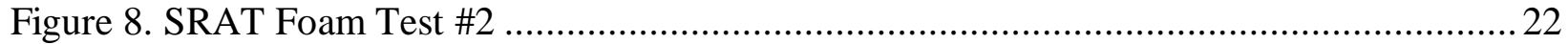

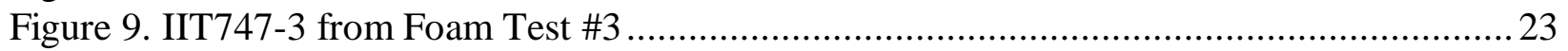

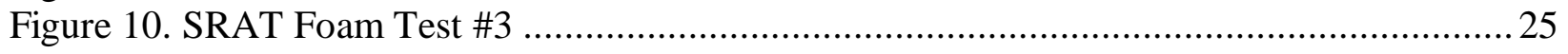

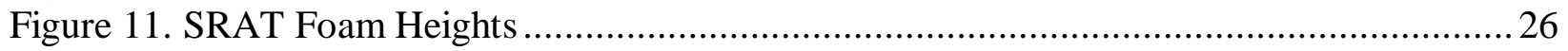

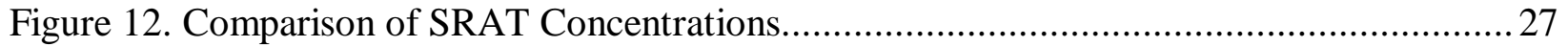

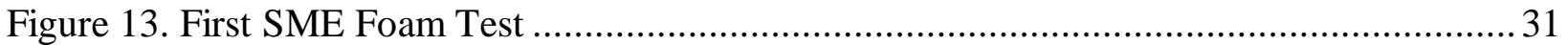

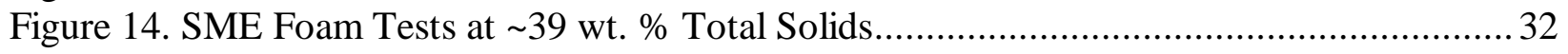

Figure 15. Side-view of the SRAT Vapor-Liquid Interface Showing the Gray Film.................... 36

\section{LIST OF TABLES}

Table I. Average SRAT Foam Heights At Initial Boiling Test ............................................. v

Table II. Summary of Simulant Preparation Results ................................................................. 6

Table III. Summary of Pseudo-steady State SRAT Trials ........................................................ 15

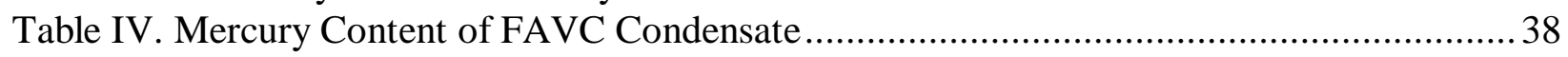

Table V. Partial Composition of Dow Corning 544 Antifoam.................................................... 40 


\section{INTRODUCTION}

The Defense Waste Processing Facility requested that the Immobilization Technology Section compare the relative foaming tendencies of sludge simulant during simulated Chemical Processing Cell operations (HLW-DWPF-TTR-99-0012) ${ }^{1}$. Dow Corning 544 antifoam, currently used in DWPF, was compared to a new antifoam formulation developed at the Illinois Institute of Technology. A task plan was written and approved ${ }^{2}$.

The task plan deliverables included a recommendation on the choice of antifoam, an evaluation of the influence of solids concentration on foaming, an evaluation on the effect of boil-up rate on foaming, an estimate of the mass of steam stripped to remove $90 \%$ of the mercury, and a determination of the fate of mercury. Additional parameters to be investigated during experimentation included the maximum foam height observed, hydrogen generation rates, and nitrite destruction rates.

Testing used a non-radioactive simulant of Tank 42 sludge. A $1 / 240^{\text {th }}$ scale mockup of the DWPF process was used to conduct the experiments. The experimental apparatus was the Glass Feed Preparation System (GFPS) installed in the SRTC Thermal Fluids Laboratory in 786-A. Two sludge-only runs of the GFPS were made. Each run simulated both the SRAT and SME processing cycles. The first run used Dow Corning 544 antifoam. The second run used IIT747 antifoam. Antifoam was added as required at a concentration of about $100 \mathrm{ppm}$ by weight on a solution basis.

\section{BACKGROUND}

The Defense Waste Processing Facility (DWPF) has experienced problems with foaming in the Sludge Receipt and Adjustment Tank (SRAT) and Slurry Mix Evaporator (SME) during transfer and processing of sludge. Excessive foaming could potentially contaminate condensate with radioactive sludge. Controlling foaming by reducing the SRAT boil-up flux extends the required stripping time for mercury. This negatively impacts DWPF by reducing throughput to the Melter Feed Tank.

A sludge-only process was developed for Tank 42 sludge ${ }^{3}$. It presumes that the addition of Dow Corning 544 antifoam will be effective in controlling foaming. The operational history for the processing of Batch 1A sludge indicates that the Dow Corning 544 antifoam is not always effective.

${ }^{1}$ Determine Effectiveness of IIT747 Antifoam for use in DWPF, December 7, 1998, TTR Number: HLWDWPF-TTR-99-0012.

${ }^{2}$ D. P. Lambert and D. C. Koopman, Comparison of Dow Corning 544 Antifoam to IIT747 Antifoam in the 1/240 SRAT, April 23, 1999, WSRC-RP-99-00205.

${ }_{3}^{3}$ D. P. Lambert and C. S. Boley, Tank 42 Sludge-only Process Development for the Defense Waste Processing Facility (DWPF) (U), WSRC-RP-98-00149, Rev. 1, September 2, 1998. 
Numerous previous pilot plant studies of the SRAT cycle have been performed, but they were not optimized for the study of foaming. Those at scales of 1/200 or larger were in metal process equipment, where foam heights and foam generation rates were not measured $^{1,2,3,4}$. Those in bench-scale glassware lacked much of the relevant physics such as bubble coalescence in a deep liquid reservoir, transport of colloidal species to the free liquid surface, comparable boil-up fluxes at the vapor-liquid interface, insignificant wall effects, etc. Many previous demonstration runs, in which foaming appeared to be inconsequential, excluded mercury and/or precious metals from the sludge simulant.

The potential formation of a colloidal suspension of elemental mercury droplets during the reduction reactions coupled with the presence of fine particles in the sludge provides a source for foam stabilizing species in the SRAT. The combination of boiling vapors and process gas evolution out of the SRAT liquid provides a source of gas bubbles. Thus, the ingredients for foaming are present. The 1/240-scale Glass Feed Preparation System (GFPS) installed in the Thermal Fluids Lab, 786-A, provides an order-ofmagnitude increase in the ratios of vessel dimensions to bubble size over that obtained in bench-scale runs. The SRAT vessel heating coils in the GFPS have the capability to reach DWPF vaporization flux levels. Liquid depths of several feet are possible. A nonradioactive Batch $1 \mathrm{~B}$ sludge simulant was used for this testing.

Laboratory development work at TNX has concluded that IIT747 antifoam is superior to Dow Corning 544 antifoam at the bench scale ${ }^{5}$. Fundamental research into foaming in three-phase systems, including coupled flow sheet simulant, completed at the Illinois Institute of Technology, IIT, under the direction of Dr. Darsh Wasan has produced a number of general conclusions ${ }^{6,7}$ :

1. A non-foaming liquid slurried with fine particles can produce a foam layer when a gas is passed through it (three-phase foam).

2. These three-phase foams are generally unstable, i.e. they must be continuously regenerated or replenished from the bubbling slurry.

3. Foam heights increase as the vertical vapor flux increases.

\footnotetext{
${ }^{1}$ J. C. Marek, Final Report on Recommended CPC SRAT/SME Foam Program, SRT-PTD-96-0076, Rev. 0, October 2, 1996.

${ }^{2}$ N. D. Hutson, Foaming and Foam Detection in the DWPF Chemical Processing Cell, WSRC-TR-9002120TL, May 1, 1990.

${ }^{3}$ S. M. Peters and J. C. Marek, Antifoam for DWPF Feed Preparation Processes, WSRC-RP-89-968, September 27, 1989.

${ }^{4}$ B. A. Halber, Foaming and Solids Carryover in the Full Scale SRAT/SME, DPST-88-381, March 3, 1988.

${ }^{5}$ D. P. Lambert, Craft Flowsheet and Antifoam Testing, WSRC-NB-97-247.

${ }^{6}$ D. T. Wasan, Foaming and Antifoaming in Waste Processing, Final Report on Subcontract No. AB84968S, Illinois Institute of Technology, Chicago, IL, September 17, 1996.

${ }^{7}$ S. K. Bindal, Study of Three Phase Foam System, Masters Thesis, Illinois Institute of Technology, Chicago, IL, December 1999; Advisor - Dr. Darsh T. Wasan.
} 
4. Smaller particles tend to support greater foam depths than comparable masses, or volume fractions, of larger particles.

5. Particles at low concentrations partially stabilize the liquid lamella between gas bubbles through processes of surface adsorption and structure formation. The presence of the solid particles in the lamella ${ }^{1}$ restricts liquid drainage and supports the foam.

6. Particles at high concentrations destabilize the liquid lamella. High concentrations of particles tend to agglomerate rather than adsorb on the bubble surface, an attractive depletion phenomena, and this promotes rupture of the foam lamella ${ }^{4}$.

7. There is at least one maximum in slurry foaminess as a function of weight per cent total solids (no foaminess at $0 \%$ solids and $100 \%$ solids, but some foaminess at intermediate values of per cent total solids).

8. There is a maximum in the foaminess of simulated coupled-process waste at intermediate solid loadings, ranging from 18-26 wt. \% total solids (depending on the choice of system studied). Testing was done at 5-18\% of the DWPF maximum boilup flux. IIT data also has a suggestion of a local minimum in foaminess in two diluted waste systems, at about 5 and $11 \mathrm{wt}$. \% total solids respectively, implying that these two systems might have more than one point of locally maximum foaminess (one between 0 and 5 or $11 \mathrm{wt}$. \% total solids and one at higher wt. \% total solids).

9. If many similar-sized particles are present, then a layered structure can form in the lamella. A single layer of solid particles lies at both gas-liquid interfaces of the lamella, a double layer of particles orients with each layer at one of the gas-liquid interfaces, a triple layer forms with the third layer in-between the two interface layers of a double layer, etc.

10. There is a hysteresis effect associated with concentration and dilution cycles. Particles that agglomerate during concentration do not necessarily separate upon dilution. Systems tend to be less foamy following concentration and re-dilution to the initial weight per cent total solids (per seven above).

11. There is a suggestion in the IIT data that the wt. \% total solids concentration giving maximum foaminess decreases as the boil-up flux increases.

12. An antifoam agent or defoaming agent could inhibit surface adsorption of particles and/or promote agglomeration of particles to destabilize the foam.

Implications for this testing from the above observations include:

\footnotetext{
${ }^{1}$ The lamella is the liquid film between two gaseous or vapor bubbles.
} 
- Non-radioactive Batch 1B sludge simulant is known to be polydisperse and will probably not form the multi-layered structures of some nearly monodisperse systems studied by IIT that contained three or more layers of solid particles in the foam lamella.

- There might be a detectable maximum in foaminess over the range of weight per cent total solids studied in the SRAT cycle (18-26\%), but it might not be observed due to the high percentage of soluble solids (9-14\%). IIT has not quantified the effect of dissolved ions on foaminess in these three-phase systems. IIT has not quantified the effect of vertical vapor flux on the location of the maximum foaminess as a function of wt. \% total solids, i.e. the point of maximum foaminess at low flux might not occur at the same wt. \% total solids as the point of maximum foaminess at a high flux.

- When the SRAT cycle sludge is concentrated and then re-diluted at a given vertical vapor flux, it is expected that less foam will form in the re-diluted state (if significant agglomeration of the sludge particles has occurred). If the sludge is later reconcentrated, a less foamy system in the concentrated state is also expected.

- Stripping of the small colloidal mercury droplets formed during SRAT acid addition should reduce the foaminess of the system.

- Frit is a "large" particle. Sludge-frit slurries should be less foamy than slurries without frit at a given wt. \% total solids.

\section{DISCUSSION}

\section{Experimental}

\section{Material Preparation}

An analysis of DWPF sample results for SRAT batches 97-102 was used to characterize the Tank 42 sludge being processed as part of Batch 1B. The elemental break-down was compared to that predicted by M. S. Hay and N. E. Bibler, and there was generally good agreement. Hay and Bibler's report ${ }^{1}$ provided the only available basis for setting the noble metal concentrations in the sludge, since noble metals are not routinely analyzed.

GFPS experimental runs for the 1999 fiscal year used most of the material in the three remaining drums of Batch One, Test Six, Optima sludge simulant ${ }^{2}$ as a feedstock. These

\footnotetext{
${ }^{1}$ M. S. Hay and N. E. Bibler, Characterization and Decant of Tank 42H Sludge Sample ESP-200, WSRCRP-98-00406, Rev. 0, June 12, 1998.

${ }^{2}$ N. D. Hutson, Revision of Batch-1 Sludge Composition for Integrated Cold Runs in the Defense Waste Processing Facility (U), WSRC-TR-95-0079, February 16, 1995.
} 
experiments included two runs for antifoam testing and two runs in support of the CST Salt Disposition alternative plus some bench-scale work.

The last three 55-gallon drums of Batch One settled sludge simulant were first decanted to increase weight per cent total solids. The resulting decanted drums were approximately $18.5 \mathrm{wt}$. \% total solids. The elemental composition of the decanted drums was compared to the analyzed DWPF and M. Hays data. The three drums were then adjusted with a combination of the previously decanted supernatant liquid, de-ionized water, aluminum oxide, manganese (IV) oxide, and nickel nitrate hexahydrate to approximately $17 \mathrm{wt}$. \% total solids (13.9 wt. \% insoluble and $3.1 \mathrm{wt}$. \% soluble solids).

The available mass of simulant in the three drums above allowed for the preparation of five 25-gallon quantities of simulant for use in the GFPS plus a small residual heel for supporting bench-scale work. Five empty drums were modified for use as GFPS feed drums. The three adjusted sludge simulant drums were each split into six parts as follows. Approximately 8.7 gallons was transferred to each of the five GFPS feed drums from each of the three adjusted simulant drums. The sequencing was randomized to minimize differences in total solids content that might result from stratification within the drum being emptied. The remaining mass, or heel, in each of the three simulant drums was transferred into a 50-liter carboy.

Each GFPS feed drum ended up with slightly more than 25 gallons. This proved fortunate later when analyses showed that the five GFPS feed drums were slightly lower in total solids than expected. The original target for batching the Sludge Receipt and Adjustment Tank, SRAT, vessel had been for 25 gallons of simulant plus 4-1/6 gallons of flush water, corresponding to 6000 gallons of sludge plus 1000 gallons of flush water in the DWPF SRAT. Actual SRAT batching was recomputed to take slightly more than 25 gallons of sludge simulant and slightly less than 4-1/6 gallons of flush water to achieve the desired target value for weight per cent total solids.

After sludge simulant had been transferred from a GFPS feed drum into the $1 / 240^{\text {th }}$-scale SRAT, the mercury, as mercury (II) oxide, and noble metals were added to complete the trimming process. Essentially identical quantities of mercury oxide and noble metals were added before processing the four feed drums used in fiscal year 1999. The mercury was brought up to $100 \%$ of Batch 1B levels. Noble metals were added at $110 \%$ of the concentrations in Hay and Bibler's report. Table II below gives the best estimates of the pre-trim and post-trim sludge simulant compositions and that of the target DWPF sludge. 
Table II. Summary of Simulant Preparation Results

\begin{tabular}{|c|c|c|c|}
\hline & $\begin{array}{l}\text { Pre-trim } \\
\text { Sludge }\end{array}$ & $\begin{array}{l}\text { Post-trim } \\
\text { Sludge }\end{array}$ & $\begin{array}{c}\text { DWPF Target } \\
\text { Sludge }\end{array}$ \\
\hline & $\begin{array}{c}\text { (No Hg \& } \\
\text { Noble Metals) }\end{array}$ & $\begin{array}{c}\text { (110\% Noble } \\
\text { Metals) }\end{array}$ & $\begin{array}{c}\text { (110\% Noble } \\
\text { Metals) }\end{array}$ \\
\hline Ag, wt. \% & 0.000 & 0.040 & 0.040 \\
\hline $\mathrm{Al}$, wt. $\%$ & 7.859 & 7.679 & 8.590 \\
\hline Ba, wt. \% & 0.005 & 0.005 & $\mathrm{n} / \mathrm{a}$ \\
\hline $\mathrm{Ca}$, wt. \% & 2.613 & 2.553 & 2.510 \\
\hline Cr, wt. \% & 0.162 & 0.158 & 0.151 \\
\hline $\mathrm{Cu}$, wt. $\%$ & 0.048 & 0.047 & 0.042 \\
\hline Fe, wt. \% & 24.373 & 23.816 & 23.461 \\
\hline $\mathrm{Hg}$, wt. \% & 0.000 & 1.050 & 1.050 \\
\hline K, wt. $\%$ & 0.157 & 0.154 & 0.234 \\
\hline Mg, wt. \% & 1.238 & 1.209 & 1.287 \\
\hline Mn, wt. \% & 3.456 & 3.377 & 3.688 \\
\hline $\mathrm{Na}$, wt. $\%$ & 7.532 & 7.360 & 6.835 \\
\hline Ni, wt. \% & 0.319 & 0.312 & 0.352 \\
\hline $\mathrm{Pb}$, wt. \% & 0.137 & 0.133 & $\mathrm{n} / \mathrm{a}$ \\
\hline Pd, wt. \% & 0.000 & 0.002 & 0.002 \\
\hline Rh, wt. \% & 0.000 & 0.006 & 0.006 \\
\hline Ru, wt. \% & 0.000 & 0.023 & 0.023 \\
\hline $\mathrm{Si}$, wt. $\%$ & 0.899 & 0.879 & 0.987 \\
\hline Sr, wt. \% & 0.029 & 0.029 & $\mathrm{n} / \mathrm{a}$ \\
\hline Ti, wt. $\%$ & 0.023 & 0.023 & 0.031 \\
\hline Zn, wt. \% & 0.152 & 0.148 & $\mathrm{n} / \mathrm{a}$ \\
\hline $\mathrm{Zr}$, wt. \% & 0.058 & 0.056 & 0.069 \\
\hline nitrite, $\mathrm{mg} /$ liter & & 7438 & 7204 \\
\hline nitrate, $\mathrm{mg} /$ liter & & 3193 & 3390 \\
\hline formate, $\mathrm{mg} /$ liter & & 116 & 601 \\
\hline chloride, mg/liter & & 89 & $\mathrm{n} / \mathrm{a}$ \\
\hline sulfate, mg/liter & & 383 & $\mathrm{n} / \mathrm{d}$ \\
\hline oxalate, mg/liter & & 240 & $\mathrm{n} / \mathrm{a}$ \\
\hline base equiv@pH 7 & & $0.362 \mathrm{M}$ & $0.132 \mathrm{M}$ \\
\hline base equiv@pH 5.5 & & $0.462 \mathrm{M}$ & $\mathrm{n} / \mathrm{a}$ \\
\hline
\end{tabular}


Analyses for anions, total and calcined solids, elements, and base equivalents in the sludge simulant were used as inputs to a spreadsheet calculation for melter feed redox based on a target waste loading in glass. The target waste loading was $35 \mathrm{wt} . \%$ sludge on an oxide basis. The redox target was 0.2 for the ratio $\mathrm{Fe}^{+2} / \mathrm{Fe}_{\text {total }}$. It was also necessary to specify the per cent excess acid to be used. A value of $150 \%$ (50\% excess) was chosen based on current DWPF practice. The spreadsheet calculated the required formic acid, nitric acid, and glass frit for use in both the SRAT and SME cycles ${ }^{1}$.

Frit 200 was obtained from DWPF for use in the antifoam test runs. The simulation assumed two major frit additions during the SME cycle. Decontamination frit slurry was not incorporated into the process simulation plan. Quantities of $\sim 90 \mathrm{wt}$. \% formic acid and $\sim 50$ wt. $\%$ nitric acid were prepared at the Multipurpose Pilot Plant Campus, TNX. These were titrated for strength (87.58-88.17\% and $49.1 \%$ respectively). The required quantities of the acids and frit for each step of the process were weighed out at TNX and transferred to the Thermal Fluids Laboratory prior to each run. Quantities of prototypical flush water associated with each of the frit additions were also prepared in advance.

Enough fresh Dow Corning 544 antifoam was obtained from the vendor to support the test run using Dow Corning 544 antifoam as a basis as well as two test runs in support of the CST Salt Disposition alternative. This material was received "full strength". A sufficient quantity of IIT747 antifoam was prepared at the Illinois Institute of Technology in Chicago to complete the corresponding antifoam test run. This material was received at " $75 \%$ of full strength". The estimated amount of antifoam required for a run assumed a 100 ppm addition of "full strength" antifoam every twelve hours of SRAT operation at boiling plus an addition immediately prior to acid addition in the SRAT cycle. Antifoam was added again at the start of the SME cycle and every twelve hours of SME cycle processing thereafter. A nominal antifoam charge was 11.2 grams of "full strength" antifoam diluted to 112 grams total with water, followed by another 112 grams of water for flushing the bottle and addition line. Consequently, the antifoam charge approached being a $5 \mathrm{wt}$. \% solution of "full strength" antifoam in water.

\section{Experimental Equipment}

The Glass Feed Preparation System, GFPS, pilot plant was used to simulate the DWPF Chemical Processing Cell equipment at $1 / 240^{\text {th }}$-scale. See the simplified schematic below, Figure 1. The GFPS is located inside the Thermal Fluids Laboratory at the Savannah River Technology Center. It consists of two 50-gallon glass vessels equipped with baffles and heating/cooling coils. The vessel simulating the DWPF SRAT and SME tanks has an air-driven agitator with two impellers. The other vessel, simulating the DWPF SMECT, has an air sparge ring. There are two glass shell-and-tube condensers. One uses process water for cooling (SRAT Condenser), while the other uses a chilled recirculating solution of ethylene glycol and water (FAVC). Liquid from the SMECT is recirculated through a glass column randomly packed with glass rings. This column performs scrubbing of the exhaust gas from the SRAT Condenser. Condensate from the

\footnotetext{
${ }^{1}$ W. E. Daniel, $1 / 240^{\text {th }}$ Sludge Only Run: Acid and Frit Calculations, SRT-PTD-99-0039, July 13, 1999.
} 
water cooled SRAT Condenser can be routed through a glass Mercury Water Wash Tank before being returned to either of the two 50-gallon vessels. Totally independent systems are in place for feeding nitric acid and formic acid. Agitator speed, SRAT/SME vessel pressure, and SRAT/SME vessel temperature are controlled from a PC-based computer control program. This program also controls numerous solenoid valves, logs electronic data automatically, and controls the setpoints of an MKS flow controller. The MKS flow controller is in charge of three air purges and a helium purge. Exhaust gas is analyzed by a gas chromatograph every three minutes.

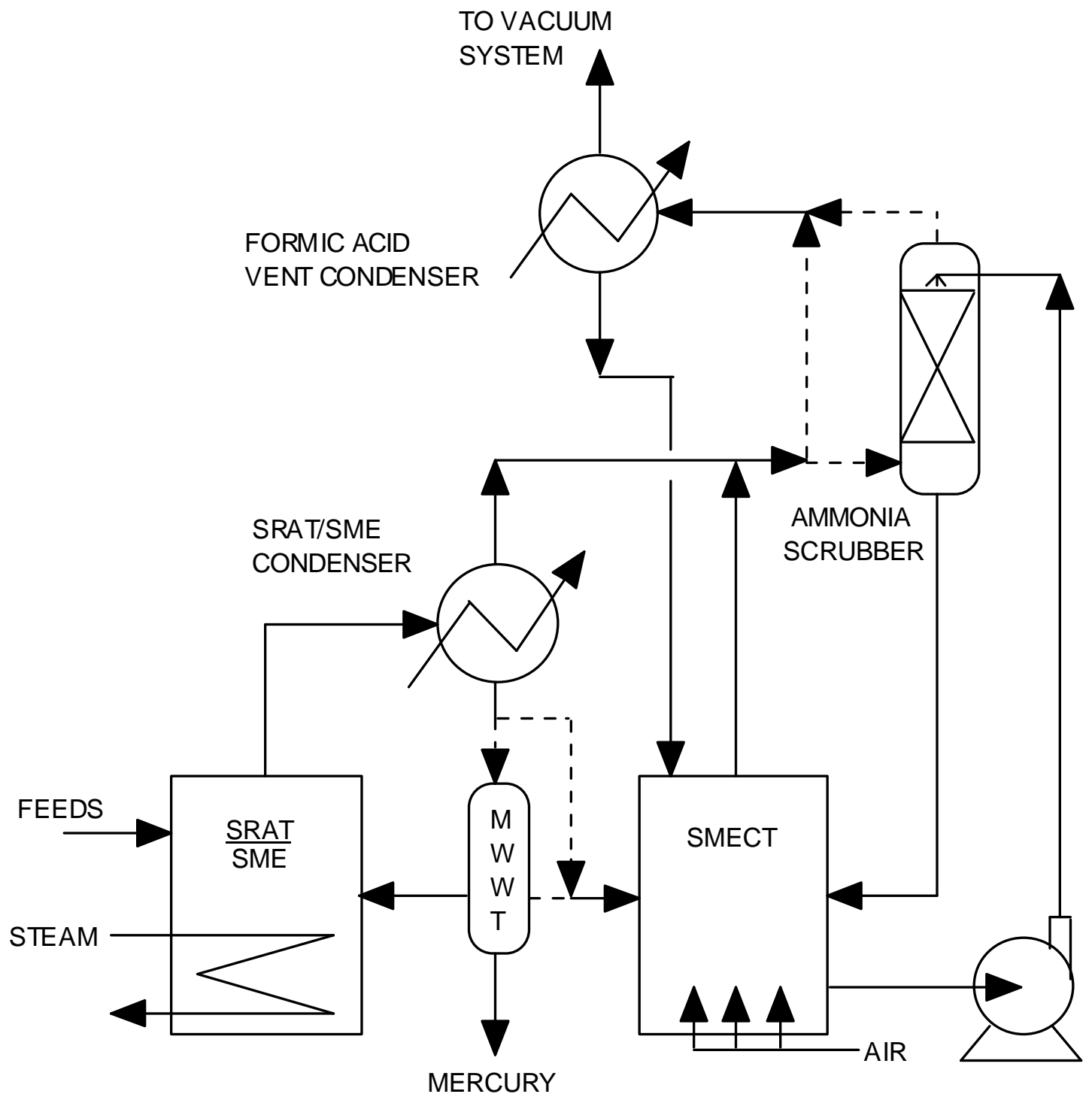

Figure 1. Schematic of the Glass Feed Preparation System.

Prior to the first experiment with chemicals, the GFPS was extensively tested with water. Key instruments were calibrated. Operating procedures, alarm procedures, and safety 
guidelines were prepared. Training of exempt personnel was completed during water runs. Training of non-exempt personnel was started during water runs, and continued through the chemical runs.

The GFPS SRAT/SME is an 18 inch diameter vessel. The typical TNX laboratory SRAT/SME vessel is four inches in diameter. Bubbles ranging from $1 / 16^{\text {th }}$ to $1 / 4^{\text {th }}$ inch diameter are not unusual in boiling simulant. The corresponding range of ratios of bubble diameters to tank diameters in switching from bench-scale to the GFPS is decreased from about $0.015-0.06$ to $0.003-0.014$. A ratio in the range of $1 / 20$ is a good upper limit for eliminating the significance of wall effects. This ratio was maintained for all normally encountered bubble sizes in the GFPS SRAT/SME.

\section{Method}

The first step in processing was to transfer the sludge simulant from one of the GFPS feed drums into the GFPS SRAT vessel. All fiscal year 1999 experiments were conducted without a SRAT heel. The contents of a drum were transferred into the SRAT with the aid of some flush water. Before and after drum weights permitted calculation of the actual mass transferred. This value, combined with the analysis for wt. \% total solids and known weight of flush water used, allowed calculation of a mass to be withdrawn from the SRAT to achieve the targets for wt. \% solids and total mass. This calculation also provided the quantity of flush water still available for use in transferring the mercury oxide and noble metals. After the excess sludge simulant mass was withdrawn, the mercury oxide and noble metals were added directly to the GFPS SRAT vessel through its chemical addition funnel. They were flushed into the sludge simulant with the remaining flush water.

Antifoam was added to the system. The temperature of the SRAT contents was raised to $93^{\circ} \mathrm{C}$ at a rate of $1^{\circ} \mathrm{C} /$ minute, using a temperature control setpoint ramping algorithm in the control computer software. When the SRAT contents reached $93^{\circ} \mathrm{C}$, the nitric acid addition was started. This was followed by a small water flush. After nitric acid line flushing was complete, formic acid addition was started. This was also followed by a small water flush. Acid and water addition took about four hours. During this time the SRAT was in temperature control at $93^{\circ} \mathrm{C}$. When formic acid line flushing was complete, the SRAT temperature was brought to boiling. About 15 minutes were needed to heat up the overhead piping to steady temperatures. This was done at total reflux via the Mercury Water Wash Tank, MWWT.

Formal foam testing began once the system was boiling at constant SRAT vapor temperature. A foam test consisted of an extended period of time under reflux at constant wt. \% total solids (assuming negligible changes in mercury, nitrite, etc.) A liquid baseline level was obtained at about $96^{\circ} \mathrm{C}$ for each test. Pseudo-steady state foam heights were measured versus time at selected boil-up fluxes. A foam test usually included foam height measurements at three different SRAT/SME steam coil flow rates. The three most commonly used steam flow rates were 25,55 , and $90 \mathrm{lb} / \mathrm{hr}$. After adjusting for heat losses in the system, biases, etc., these correspond closely to boil-up fluxes of $27 \%, 61 \%$, 
and $107 \%$ of the maximum DWPF boil-up flux of $44.2 \mathrm{lb} / \mathrm{hr} / \mathrm{ft}^{2}(5000 \mathrm{lb} / \mathrm{hr}$ in a $12 \mathrm{ft}$. diameter SRAT). The $27 \%$ flux corresponds to $1 / 240^{\text {th }}$ of the DWPF boiling rate of 5000 $\mathrm{lb} / \mathrm{hr}$, i.e. is the scaled prototypical boil-up mass flow rate.

The $1 / 240^{\text {th }}$-scale GFPS SRAT can operate at either the DWPF boil-up flux or the DWPF boil-up rate, but not at both simultaneously. The vessel geometry that permits this requires a vessel with the same depth of liquid as the full-scale SRAT in DWPF. This was not practical in the current laboratory facilities. Consequently, there was a departure from prototypical operation in the sense that either the boil-up flux or rate (or both) was not matching that of the full-scale SRAT at any given point in the experiment.

During a formal foam test, pseudo-steady state foam height data at a specified boil-up flux was taken for a twenty minute period. The twenty minute interval was originally selected based on the combined dynamics of the GFPS steam boiler and steam coil, which have a cycle of roughly five minutes. Twenty minutes gave several boiler cycles, which eliminated that as a factor in data analysis. In the actual experimental runs the foam layer rose or fell quickly to a new level when the steam flow rate was changed. This change occurred within two to three minutes. In most cases the top of the foam layer would appear to oscillate about a steady mean value for the balance of the twenty minutes, i.e. a pseudo-steady state foam was formed. The magnitude of the foam height oscillation was noted in addition to the mean value.

Attempts were made to characterize the bubble size near the wall, the depth at which bubbles could be seen at the wall, whether or not the bubbles near the wall were rising or being drawn down by the liquid from the collapsing froth above them, etc. A dried sludge coating formed on the vessel wall over time which interfered with the ability to observe some of these phenomena. Some digital images and video were obtained.

After the first foam test came a series of concentration steps as well as a dilution step of the SRAT contents. Additional foam tests were conducted following each of these steps. The dilution step allowed retesting one or two of the earlier foam test total solids concentrations. This permitted some examination of the effect of time-dependent background processes on foam heights. SRAT cycle pseudo-steady state foam tests occurred at roughly 18, 21 and $26 \mathrm{wt}$ \% total solids. Dynamic, or time dependent, foam height data was obtained during some of the concentration steps in between the pseudosteady state tests. The dynamic foam height data provides a more detailed look at the effect of wt. \% total solids on foaminess. Testing occurred for about eleven hours per day. The process would be shut down in the evening and restarted the following morning. This was another departure from prototypical operation.

Condensate collection rates in the SMECT were measured during some of the concentration steps. The condensate collection rate data was taken to further validate the accuracy of the steam flow measurement, which used an orifice plate and 0-100 inch differential pressure transmitter. The steam flow meter had been calibrated during waterrun tests prior to foam testing, however this number was critical to the evaluation of the 
foam data. Therefore additional measurements were made to protect the integrity of the data.

Figure 2.

\section{Correlation of Boil-up Flux with Steam Flow}

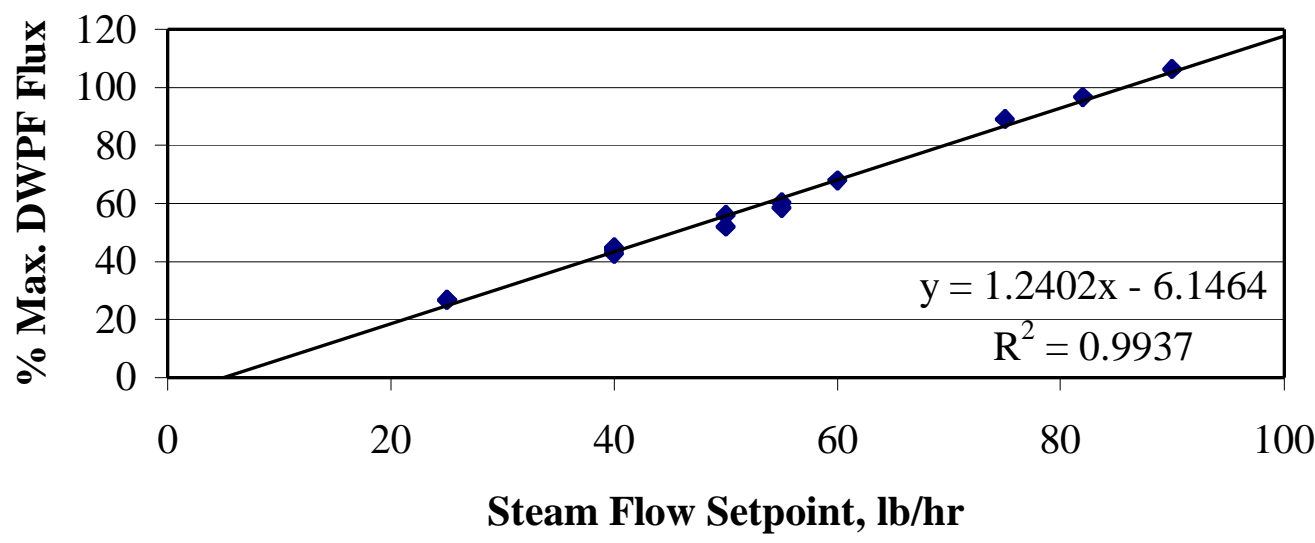

A simulation of the DWPF SME cycle followed the SRAT cycle. A combination of Frit 200, water, and formic acid was added to the main process vessel, which was then designated as the SME. No heel was simulated in the SME cycle. The SME contents were brought to boiling at steady state under reflux, and then a foam test was performed. Following the first SME foam test, the SME was concentrated to reduce volume and make room for the second frit-water-formic acid addition. At the end of the concentration period, a second SME foam test was performed. The second frit addition was made. The SME was then brought to boiling, and a third SME foam test was performed.

After foam testing, the SME was concentrated to a targeted wt. \% total solids in excess of $45 \%$. It was ultimately desired to have approximately $45 \mathrm{wt}$. \% total solids in the product drum. The water needed to dilute the SME product back to $45 \mathrm{wt}$. \% total solids was used to flush the vessel after the initial transfer of SME product to a drum. It was not practical to concentrate beyond 48-50 wt. \% total solids, because the SME cooling coils are physically above the steam coils. If the SME product had been concentrated further, then the entire cooling coil would have been in the vapor space.

Melter feed simulant from the first run (with Dow Corning 544 antifoam) was used to validate the Engineering Development Section's mock-up of the SME Hydragard sampling loop as part of the CST Salt Alternative work ${ }^{1}$. It was reused by them in a second study on Hydragard sampler modifications.

${ }^{1}$ Z. H. Qureshi, Mixing and Sampling of Sludge-Frit-CST Slurries (U), September 1999, WSRC-TR-9900309. 
A GFPS experimental run was expected to last four 12-hour days. Additional time was taken to prepare chemicals, transport drums, clean equipment, etc. SRAT batching, once the drums, chemicals, etc. were at Thermal Fluids Laboratory, took about five hours. Under ideal conditions the SRAT cycle took about 18 hours to complete as measured from the time the steam boiler was turned on until the time the SRAT was cool enough for frit addition. The SME cycle could be completed in about 12 hours if the concentration steps were done at high steam flow rates, 60-90 lb/hr. A more typical SME cycle lasted about 16 hours. Post-SME cycle work involved transferring melter feed simulant to a drum, draining the SMECT and MWWT, and flushing/cleaning the SRAT/SME vessel. This took 4-12 hours depending on the extent of SRAT cleaning.

Consequently, the actual processing, or work with sludge, took about five days of 12hour shifts. This reflects the time needed to shut down and start up the equipment four additional times, as well as the time required to fix various problems such as pump failures, plugged lines, malfunctioning gas chromatographs, computer glitches, etc. The runs were normally supported by two exempt and two non-exempt persons. Sometimes there were three exempts or three non-exempts rather than two. Major activities like start-up, batching, frit addition, foam testing, and shut down went more smoothly when at least three people were available.

An unexpected bonus for the foam test study developed during the course of the investigations into the CST Salt Disposition alternative. Two runs were made in the GFPS in support of the CST Salt Disposition alternative ${ }^{1}$. These runs included SRAT and SME cycles. A water slurry of CST was added in two steps during the middle of the SRAT cycle. The SRAT cycle steps prior to the first CST addition, however, were identical to those at the start of the Dow Corning 544 antifoam test run (the first foam test and initial boil-down to reduce liquid volume in the vessel). This additional data helped in developing an understanding of the reproducibility of the foam height data.

\section{RESULTS}

\section{Qualitative Observations}

A number of noteworthy qualitative observations arose during the course of the antifoam experimental work. Some of these included:

- Uncontrolled foaming could occur at virtually any point in the SRAT or SME cycle, if enough time had passed since the last antifoam addition.

\footnotetext{
${ }^{1}$ D. C. Koopman and D. P. Lambert, Hydrogen Generation and Foaming During Tests in the GFPS Simulating DWPF Operations with Tank 42 Sludge and CST (U), September 3, 1999, WSRC-TR-9900302.
} 
- Both Dow Corning 544 and IIT747 antifoam were very effective at controlling foaming during the SME cycle.

- Dow Corning 544 and IIT747 antifoam were only moderately effective at controlling foaming in the last third of a twelve hour SRAT cycle and roughly comparable to each other.

- Adding IIT747 antifoam to a system already foaming uncontrollably essentially eliminated the foam (brought the system back under moderate to effective foaming control).

- Fresh Dow Corning 544 antifoam at 100 ppm was not effective at controlling foaming when the SRAT was first brought to boiling at $61-107 \%$ of the DWPF boilup flux, even if it had just been added.

- IIT747 antifoam at 100 ppm was effective at controlling foaming when the SRAT was first brought to boiling at $107 \%$ of the DWPF maximum boil-up flux.

- During formic acid addition, a lot of fine gray material was incorporated into the frothy layer on top of the sludge slurry (see Figure 15). This was probably reduced mercury in the form of colloidal droplets. The gray layer seemed to be mostly gone by the start of the second foam test. When sludge containing higher mercury levels is eventually processed in DWPF, the mercury component of the froth can be expected to persist into later stages of the SRAT cycle causing as yet unidentified foaming problems.

- Even when either antifoam had just been added to the sludge simulant at boiling, the height of a steady froth layer of bubbles was several times greater than that observed with water under the same conditions. This is presumably related to intrinsically different properties of the sludge simulant relative to water and is independent of the antifoam agent.

- IIT747 antifoam at 100 ppm added early in the morning of a SRAT cycle processing day remained effective at controlling foam during 10.5 consecutive hours of processing at elevated temperature. The data indicate that foaminess was beginning to increase after about eight hours. Boiling was stopped after 10.5 hours.

- IIT747 antifoam added in the middle of SRAT formic acid addition did not last overnight. Total elapsed time was 17.5 hours, of which about five hours were at temperatures above $90^{\circ} \mathrm{C}$. This would not be a normal event in DWPF, but a similar situation could occur if there was an equipment malfunction requiring a temporary termination of operations. 
- It was noted in bench scale work at TNX that IIT747 antifoam added at $100 \mathrm{ppm}$ permitted an abnormal amount of form to form during SRAT acid addition. These were in four-liter vessel runs using all formic acid at $150 \%$ calculated acid with Tank 42 sludge simulant. Adding additional IIT747 antifoam defoamed the sludge. Taken with the above point, it is recommended that IIT747 antifoam either be added again at the $100 \mathrm{ppm}$ level between nitric acid and formic acid additions in DWPF, or added at $150 \mathrm{ppm}$ rather than $100 \mathrm{ppm}$ prior to the start of acid addition.

- IIT747 antifoam added after the first frit-water-formic acid addition in the SME cycle did not last over a weekend in the SME cycle. The vessel would likely have foamed over if the boil-up flux had been raised to the DWPF maximum. Total elapsed time was 71 hours, of which about five hours were at boiling, and at least 64 hours were at less than $50^{\circ} \mathrm{C}$. The last two observations together suggest that time may be more important than temperature in destroying antifoam.

\section{Quantitative Observations -- Foam}

The discussion of quantitative foam height observations below is divided into five sections. All SRAT foam height data at about $18.2 \mathrm{wt}$ \% total solids are discussed under "SRAT Foam Test \#1". All SRAT data at about $21.4 \mathrm{wt} . \%$ total solids are discussed under "SRAT Foam Test \#2". All SRAT data at about $26.5 \mathrm{wt}$. \% total solids are discussed under "SRAT Foam Test \#3". Foam height data from the SRAT concentration steps in between these foam tests are discussed fourth. SME data is discussed last. (There were no quantitative observations of foam during SRAT cycle acid addition. Minimal foam was present except following a long outage due to acid pump maintenance in the IIT747 antifoam run.)

A system of shorthand nomenclature will be used below to label the various foam tests. DC544 will be short for Dow Corning 544 antifoam. IIT747 will be short for IIT747 antifoam. Table III below summarizes the conditions at the beginning of each of the thirteen pseudo-steady state foam tests. Measured wt. \% total solids generally run 2-3\% lower than the values predicted from material balance considerations. Part of this difference is due to the model retaining all non-water species as solids throughout the duration of the SRAT cycle, up to a $1.2 \%$ effect. Part of this difference is due to loss of volatile species during oven drying, often 1-2\%. Part of this difference is potentially due to non-representative sampling of the SRAT contents. Soluble solids start at about 9.4 wt. $\%$ following acid addition and increase to about $14.6 \mathrm{wt}$. \% by the end of the SRAT cycle.

"Age of Antifoam" is measured from the time antifoam was last added to the start of the foam test. Antifoam ages by about 63 minutes on average during a Foam Test. "DWPF lb of Steam Fed" represents the equivalent pounds of water boiled from the SRAT at DWPF-scale at the start of the foam test. This number increases by about $14,000 \mathrm{lb}$ during a foam test. Details of the nature of any repeated trials will be given in the text where appropriate, e.g. DC544-1A versus DC544-1B. Foam heights for the SRAT and 
SME cycle tests were typically in the range of 2-20 inches. Under certain test conditions, as described below, even higher foam heights could have been obtained if a taller SRAT/SME vessel had been available.

Table III. Summary of Pseudo-steady State SRAT Trials

\begin{tabular}{|c|c|c|c|c|}
\hline Foam Test & $\begin{array}{l}\text { Wt. \% Total } \\
\text { Solids-Theory }\end{array}$ & $\begin{array}{l}\text { Age of Anti- } \\
\text { foam, minutes }\end{array}$ & $\begin{array}{l}\text { DWPF lb of } \\
\text { Steam Fed }\end{array}$ & $\begin{array}{l}\text { Nitrite ion, } \\
\text { mg/liter }\end{array}$ \\
\hline DC544-1A & 18.2 & 105 & 0 & 1750 \\
\hline DC544-1B & 18.3 & 10 & 0 & 2526 \\
\hline DC544-1C & 18.2 & 10 & 0 & 3067 \\
\hline DC544-2 & 27.0 & 395 & 45,000 & 450 \\
\hline DC544-3 & 32.4 & 125 & 75,000 & 280 \\
\hline DC544-4 & 21.5 & 252 & 95,000 & 130 \\
\hline DC544-5 & 26.3 & 397 & 125,000 & 56 \\
\hline IIT747-1A & 18.2 & 23 & 0 & 2800 \\
\hline IIT747-1B & 18.2 & 10 & 14,000 & -- \\
\hline IIT747-2 & 21.4 & 161 & 40,000 & 809 \\
\hline IIT747-3 & 26.3 & 312 & 70,000 & 296 \\
\hline IIT747-4 & 21.3 & 431 & 90,000 & 189 \\
\hline IIT747-5 & 26.5 & 567 & 120,000 & 86 \\
\hline
\end{tabular}

\section{SRAT Foam Test \#1}

A total of four pseudo-steady state foam tests were run at approximately $18.2 \mathrm{wt}$. \% total solids at the start of SRAT cycle boiling. These came from four SRAT cycle runs in the GFPS, two from the antifoam test program and two from the CST Salt Disposition alternative testing. These foam tests were always the initial foam test of a run because of the low solids loading.

Three different tests used Dow Corning 544 antifoam. These came from the Dow Corning 544 antifoam test run (DC544-1A) and the two CST Salt Alternative test runs (DC544-1B and DC544-1C). Two tests came from the one run with IIT747 antifoam (IIT747-1A and IIT747-1B). The first test came late in the day (IIT747-1A), and the system was shut down afterwards. On the following day the system was brought to boiling without adding antifoam. Uncontrolled foaming was observed, and fresh antifoam was added which immediately collapsed the foam. The first two fluxes of the previous day's foam test were then repeated for comparison purposes (IIT747-1B). Figure 3 below shows the extent and nature of foaming just prior to adding fresh antifoam as just described. The appearance of bubbles in photo and video images changed with lighting angle. In some instances bubbles appear bright and white, e.g. left of center below; in other instances dark and black, e.g. right of center below or in Figure 6. 


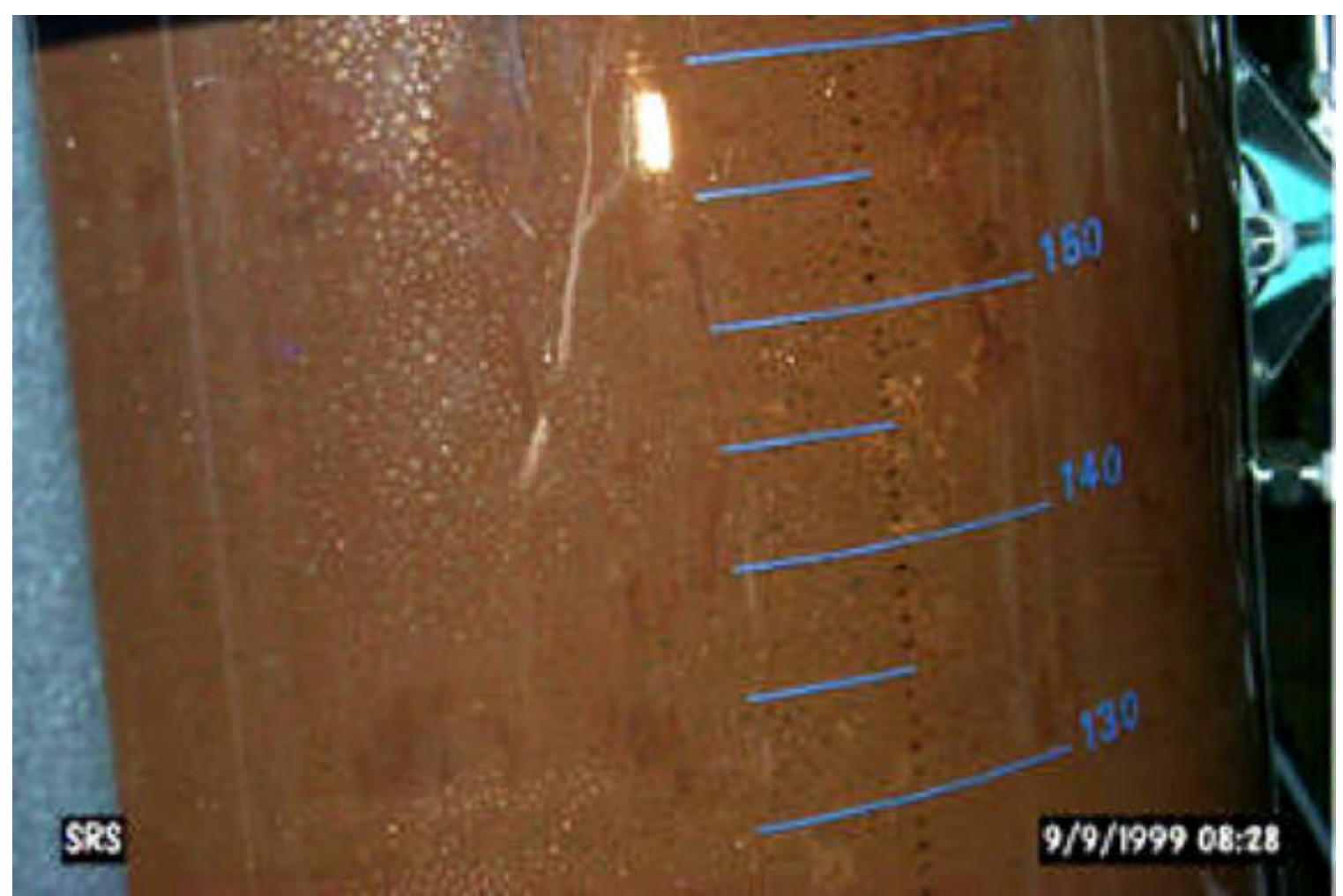

Figure 3. SRAT Foam at $27 \%$ of DWPF Maximum Boil-up Flux with Spent IIT747 Antifoam. The image spans a depth of about nine inches of foam.

Figure 4 below gives a graphical comparison of foam height data from the four foam test runs comprising SRAT Foam Test \#1 (three with DC544 and one with IIT747). The foam height scale zero represents the baseline liquid level at $96^{\circ} \mathrm{C}$ of about 31 inches. The 17.6 inch scale maximum represents the vessel lid location. The $27 \%$ maximum flux test was run first in DC544-1A, and then it was repeated following the two tests at $61 \%$ and $45 \%$ maximum flux. That is why there are two data points for this test at $27 \%$. 
Figure 4. SRAT Foam Test \#1.

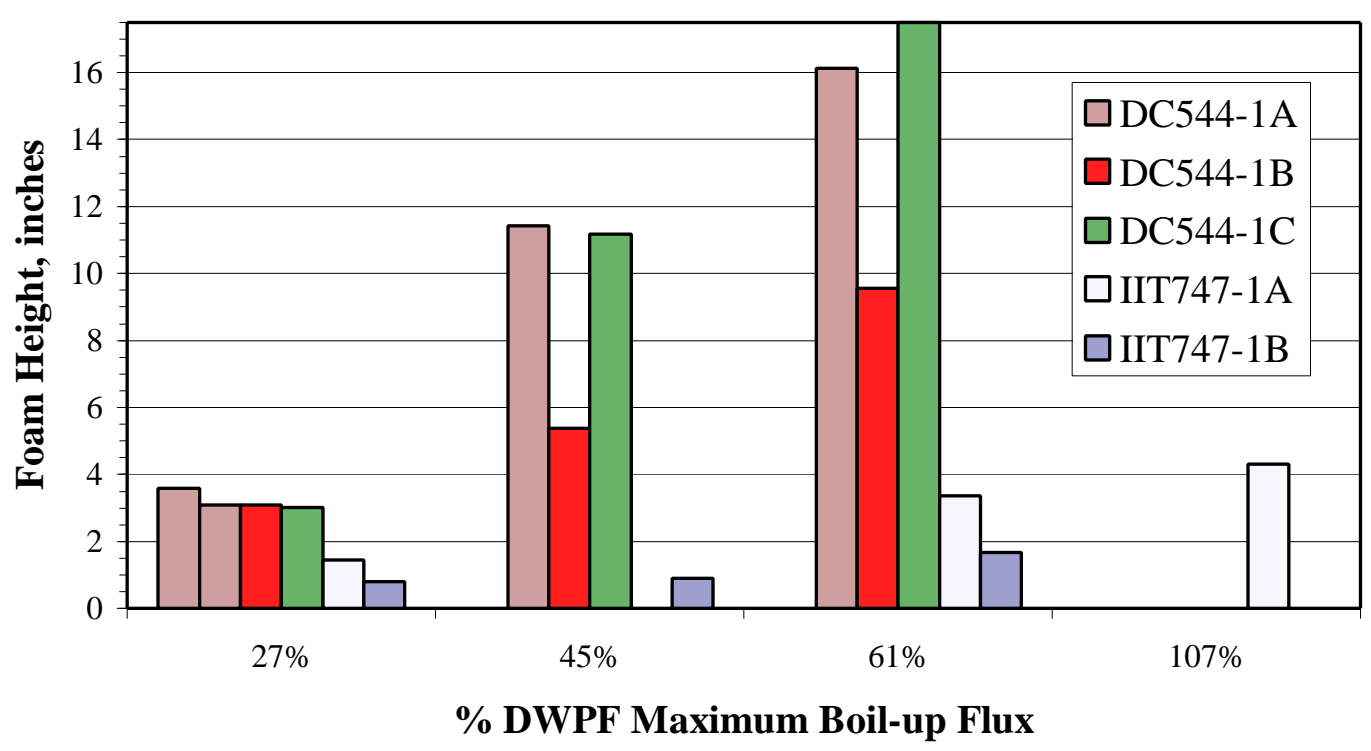

Considerable foaming was observed in all tests with Dow Corning 544 antifoam even though antifoam had been added within the past one to two hours. The original plan called for testing at $27 \%, 61 \%$, and $107 \%$ of the DWPF maximum boil-up flux. In none of these three tests was the boil-up flux raised to $107 \%$ and held there, since foam filled the SRAT at lower fluxes. Tests at $45 \%$ of the DWPF maximum boil-up flux were substituted for tests at $107 \%$.

In all three Dow Corning 544 runs at $27 \%$ flux (four data points) the foam was dynamically stable, neither increasing nor decreasing on average over time, and about 3 to 3.5 inches deep. At a flux of $45 \%$, the foam height varied between five and twelve inches in these three tests.

Foam rose to just below the lid, about $16.3 \pm 1$ inches high, at a flux of $61 \%$ in DC5441A. Foam height steadied out just enough to complete the twenty minute test. During DC544-1C, the foam rose nearly as high as the lid as soon as the flux was increased to $56 \%$, and no foam test could be completed at $61 \%$. The foaming tendency during the DC544-1B test was lower, and only about 10 inches of foam formed at $61 \%$. After the $61 \%$ foam test in DC544-1B, the boil-up flux rate was increased gradually to $82 \%$ at which point the foam again filled the SRAT to the lid. The reason(s) for these variations between runs was not identified. It is worth noting that the observed foams seemed to have an upper bound on their height as opposed to growing continuously with time. This probably represents a dynamic balance between the rate of transport of liquid into the foam layer by the vapor flux with the rate of drainage back down through the bubble lamellae (presumably driven by gravity). 
In contrast, very little foaming was observed in the equivalent flux foam tests with IIT747 antifoam. A test was successfully completed at $107 \%$ of the DWPF maximum boil-up flux on the first day with only about 4.5 inches of foam, i.e. a fairly shallow foam layer. Foam heights were even less at lower boil-up fluxes. When the tests were repeated the second day, the SRAT was brought back to boiling without adding fresh antifoam to see what effect time would have on the antifoam. (The antifoam addition strategy called for adding fresh antifoam every twelve hours.) Over eight inches of foam developed at just $27 \%$ of the maximum DWPF boil-up flux (very unusual at this flux). IIT747 antifoam was then added, and the foam height fell to less than one inch.

The overall differences between Dow Corning 544 antifoam and IIT747 antifoam were very pronounced in SRAT Foam Test \#1. Dow Corning 544 antifoam was ineffective at controlling foam height as boil-up flux was increased to the DWPF maximum. Dow Corning 544 may have been keeping the rate of increase in foam height versus time under control, i.e. preventing uncontrolled foam growth that would have filled the free volume in the vessel with foam regardless of the available free space. IIT747 antifoam was extremely effective at controlling foam height and growth under the conditions in Foam Test \#1, i.e. foam heights were near their minimum observed values at the various fluxes.

Figure 5 represents an attempt to correlate the foam height to the evaporative flux in the SRAT. It is assumed in the regressions that the foam height is zero at zero flux. A plot showing foam height going to zero as boil-up flux goes to zero in some manner was expected. The dependence of foam height on boil-up flux appeared to be stronger than first order in SRAT Foam Test \#1, i.e. upward curvature was suggested by the actual data. Another way of saying this was that foaminess was less than expected at $27 \%$ flux but more than expected at $61 \%$ flux for a linear model. The actual reasons for the observed behavior in Figure 5 could be considerably more complex. An example of a mechanism that would add complexity would be a variable dependency of the point of maximum foaminess on the wt. \% total solids at various boil-up fluxes. 
Figure 5. Regression for SRAT Foam Test \#1.

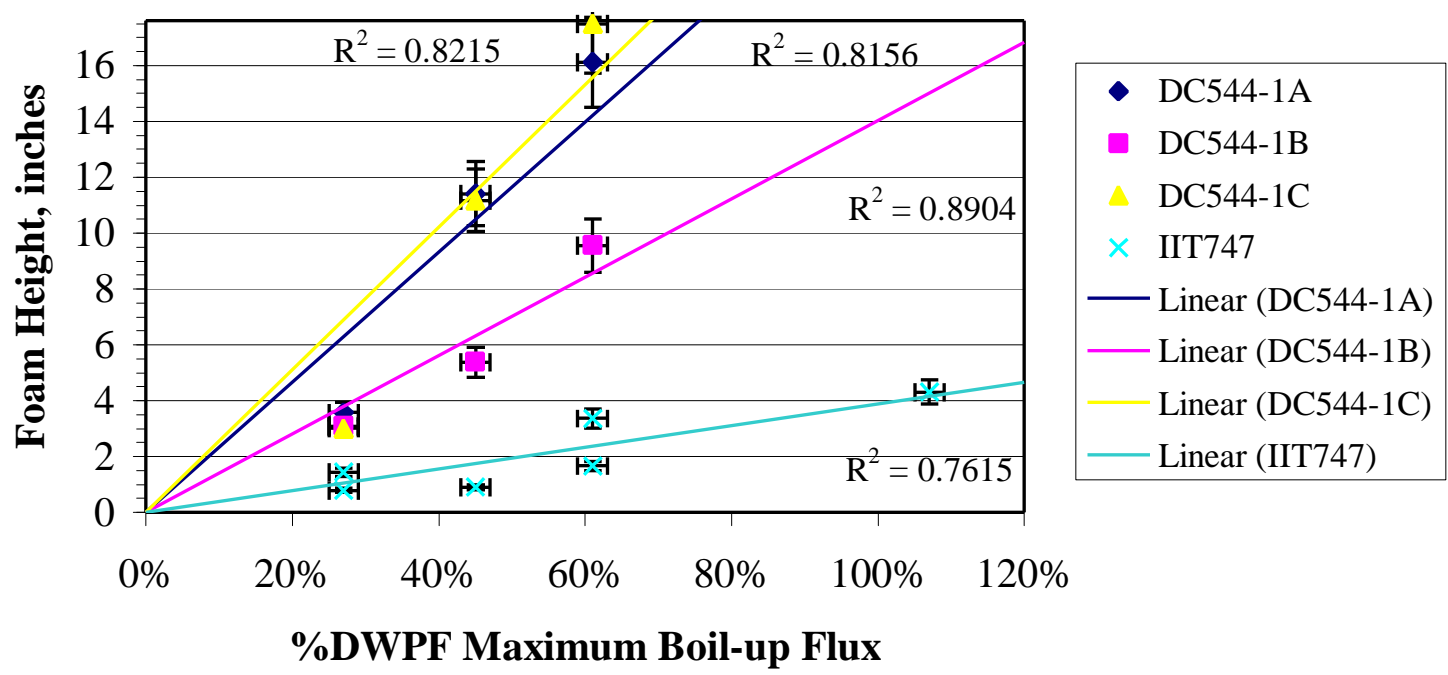

The foams observed above were transient foams that required a continuous boil-up flux to sustain themselves. They tended to collapse quickly when the boiling vapor supply was removed. There were also sporadic eruptions of slurry droplets greater than an eighth-inch in diameter to heights of perhaps a half a foot above the top of the foam. These eruptions became worse as flux was increased. Entrained sludge solids gradually accumulated in the inlet head of the SRAT condenser. The foams were very thick in appearance and seemed to incorporate a large amount of liquid slurry into the lamellae (bubble walls). Foam was visually opaque over less than one-inch paths. There were many bubbles in the 0.05-0.25 inch diameter range, Figure 6. In this figure the foam bubbles show as dark spots, or shadows. Most of the visible spots are in the top half of the image, which was taken near the baseline liquid level. The bubbles visible in the image are primarily $1 / 16^{\text {th }}$ to $1 / 8^{\text {th }}$ inch in diameter, although smaller bubbles are also present. 

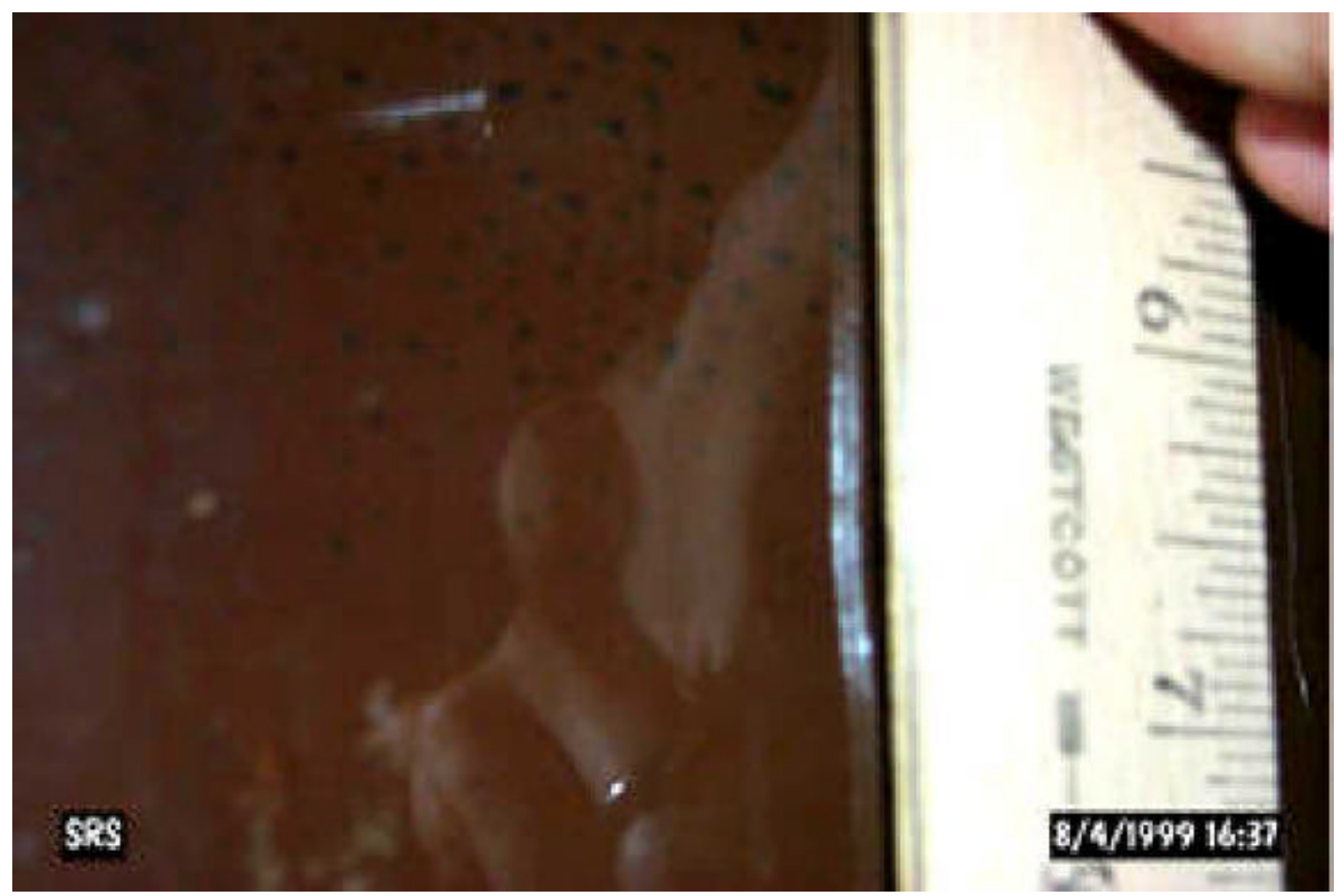

Figure 6. Foam in DC544-1C at 27\% DWPF Maximum Boil-up Flux.

In contrast, the foam observed once during SRAT formic acid addition (prior to either boiling or to SRAT Foam Test \#1) appeared to be a self-sustaining and self-supporting foam. It was comprised of large thin-walled bubbles that were relatively stationary. Enough light was transmitted through the foam to be visible to the naked eye from one side to the other, i.e. through 18 inches. The maximum flux due to gas generation during acid addition appeared to be about 20 times smaller than the lowest boil-up flux studied, i.e. about $1 \%$ of the maximum DWPF boil-up flux.

\section{SRAT Foam Test \#2}

Three pseudo-steady state foam tests were run at approximately $21.4 \mathrm{wt}$. \% total solids during the middle of the SRAT cycle. One test used Dow Corning 544 antifoam and occurred as the fourth foam test in that run, DC544-4. Two tests came from the run with IIT747 antifoam. These were the second and fourth foam tests in that run, IIT747-2 and IIT747-4. All three $21.4 \%$ foam tests successfully studied foam height at $27 \%, 61 \%$, and $107 \%$ of the DWPF maximum boil-up flux. Foam did not threaten to go above the vessel lid.

Concentration just before and after IIT747-2 took place at fluxes of $38 \%$ and $45 \%$ of the DWPF maximum. This provided some additional flux dependence data beyond that obtained during the pseudo-steady state test. (Note: foam height data taken during the concentration steps was fairly accurate just before or after a foam test, because an 
accurate liquid baseline was always determined for a foam test. Consequently the baseline estimation error during a concentration step goes to zero as the process nears one of the pseudo-steady state test points. Foam height data from concentration steps does lack the twenty minute averaging of the pseudo-steady state foam tests. This does not appear to be especially detrimental).

Figure 7 shows a nearly linear dependence between the foam height and boil-up rate. It includes data from the three pseudo-steady state flux tests plus the before and after concentration steps. The foam height zero corresponds to a baseline liquid depth of about 25 inches. The regression was forced through the origin. Error bars are measurement uncertainties in foam height and conversion uncertainties between steam coil flow and boil-up flux. It is not clear why this data is not more similar in appearance to Figure 5 for Foam Test \#1, where upward curvature was suggested.

Figure 7. IIT747-2 from Foam Test \#2.

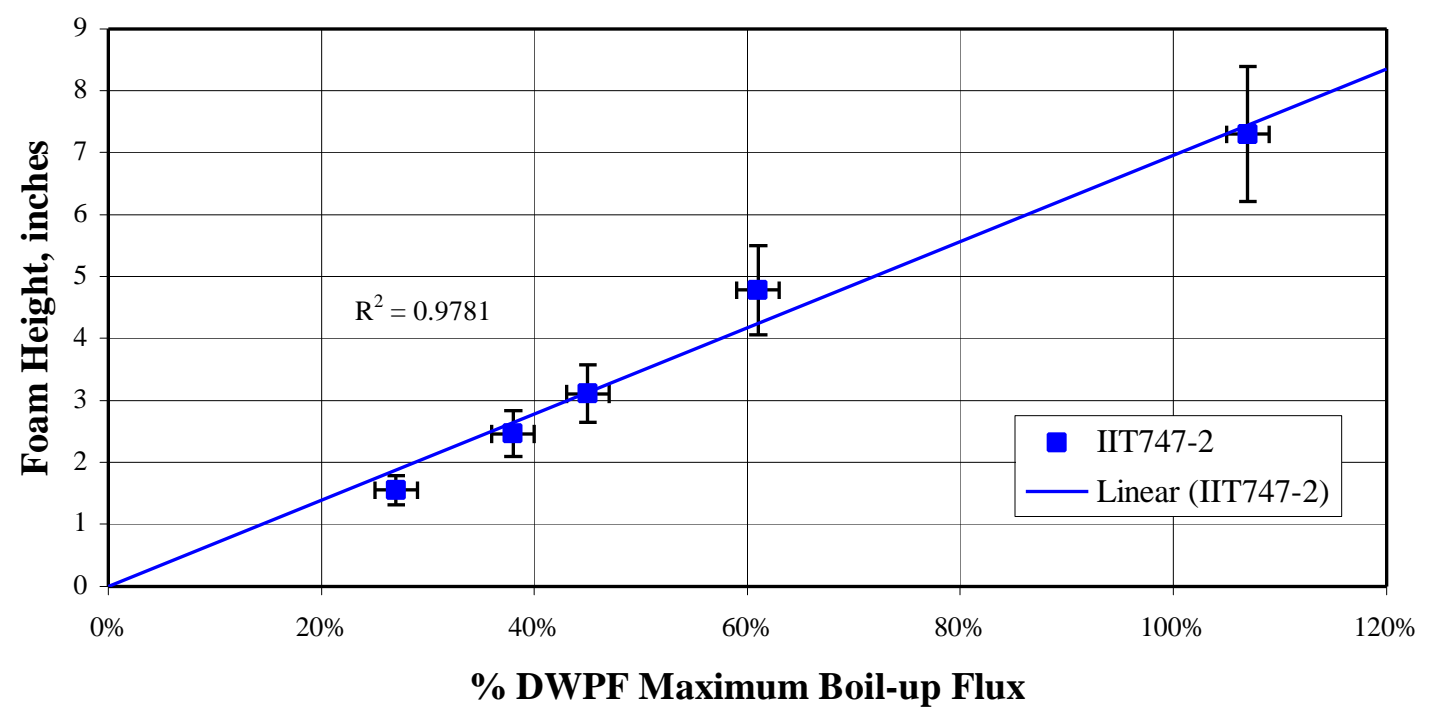


Figure 8 presents a side-by-side comparison of foam heights from the three pseudosteady state boil-up flux tests. DC544-4 and IIT747-4 are the most directly comparable from the standpoint of processing history, although all three are at essentially the same wt. \% total solids. DC544-4 and IIT747-4 have undergone approximately the same amount of steam stripping and have similar nitrite ion concentrations, see Table III above. Roughly equivalent mercury concentrations were expected for this pair based on their steam stripping equivalence. Uncertainties in foam heights should be taken as plus or minus about one-half inch.

Figure 8. SRAT Foam Test \#2.

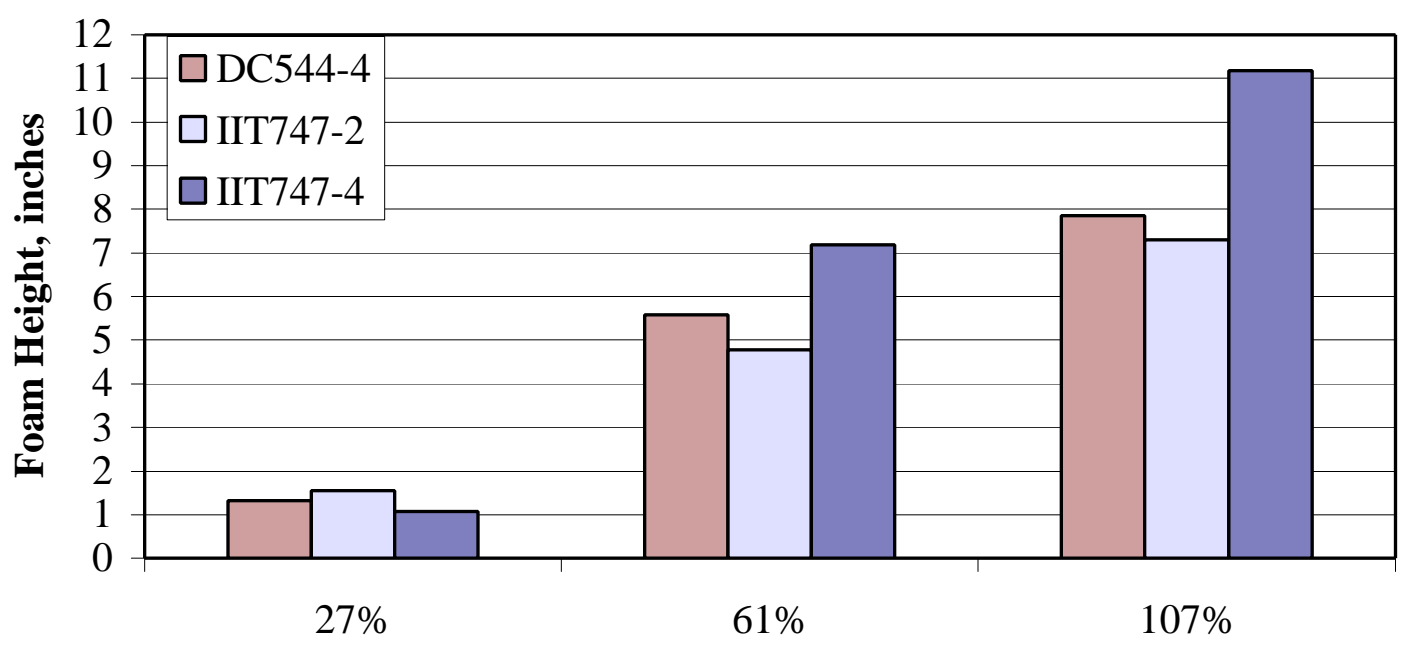

\% DWPF Maximum Boil-up Flux

Both antifoams were just moderately effective at controlling foam height over the range of boil-up fluxes studied. Neither antifoam was effective at eliminating the foam, i.e. limiting the foam height to just a few inches. This could be due to aging of the antifoam. One explanation for the greater foam heights at $61 \%$ and $107 \%$ in IIT747-4 versus IIT747-2 could be that the antifoam was 2.7-3.7 hours old during test IIT747-2, while it was 7.2-8.2 hours old during test IIT747-4. The negative effect of aging antifoam could be more important than the anticipated positive effect of removing mercury by steam stripping, especially if most of the mercury had been stripped prior to test IIT747-2. Observed foam heights at $61 \%$ and $107 \%$ flux were greater at $21.4 \mathrm{wt}$. \% total solids than at $18.2 \%$ for the IIT747 antifoam run. Conversely, foam heights at $61 \%$ (and implicitly at $107 \%$ ) flux decreased in the runs with Dow Corning 544 antifoam as the system went from $18.2 \%$ to $21.4 \mathrm{wt}$ \% $\%$ total solids.

\section{SRAT Foam Test \#3}

Four pseudo-steady state foam tests were run at approximately $26.5 \mathrm{wt}$. \% total solids, two with each antifoam. These tests were in the middle and at the end of the SRAT 
cycle. All four tests successfully studied foam height at $27 \%, 61 \%$ and $107 \%$ of the DWPF maximum boil-up flux. Concentration before IIT747-3 took place at $40 \mathrm{lb} / \mathrm{hr}$ steam flow. This provided an additional data point at a fourth boil-up flux.

The DC544-5 and IIT747-5 test data was the most directly comparable from a processing history standpoint, see Table III above, although all four tests were at essentially the same wt. \% total solids. The IIT747-5 test was designed so that the total pounds of steam evaporated from the SRAT at the start of the test matched as closely as possible the equivalent total for the DC544-5 test. The actual match was 125,000 vs. 120,000 pounds steam at DWPF-scale. Mercury concentration was also roughly equivalent for this pair, 0.059 wt. \% vs. 0.067 wt. \%. IIT747-3 was intended to be a comparison in time for IIT747-5. DC544-2 serves roughly the same purpose for DC544-5. IIT747-3 and DC544-2 were not designed to be comparable other than on a wt. \% total solids basis.

Figure 9 shows raw foam height data for IIT747-3 versus condensate generation rate. The SRAT contents are at their lowest level in the vessel during these tests, just over 20 inches. This plot is typical of the data from the other three foam tests in Foam Test \#3. The foam height does not obviously extrapolate to zero at zero boil-up flux, but to two to six inches depending on the foam test selected. If the plot were forced through the origin, it would imply downward curvature. This would then give a progression of upward curvature to linear to downward curvature with increasing wt. \% total solids over the range studied, Figures 5, 7 and 9.

Figure 9. IIT747-3 from Foam Test \#3.

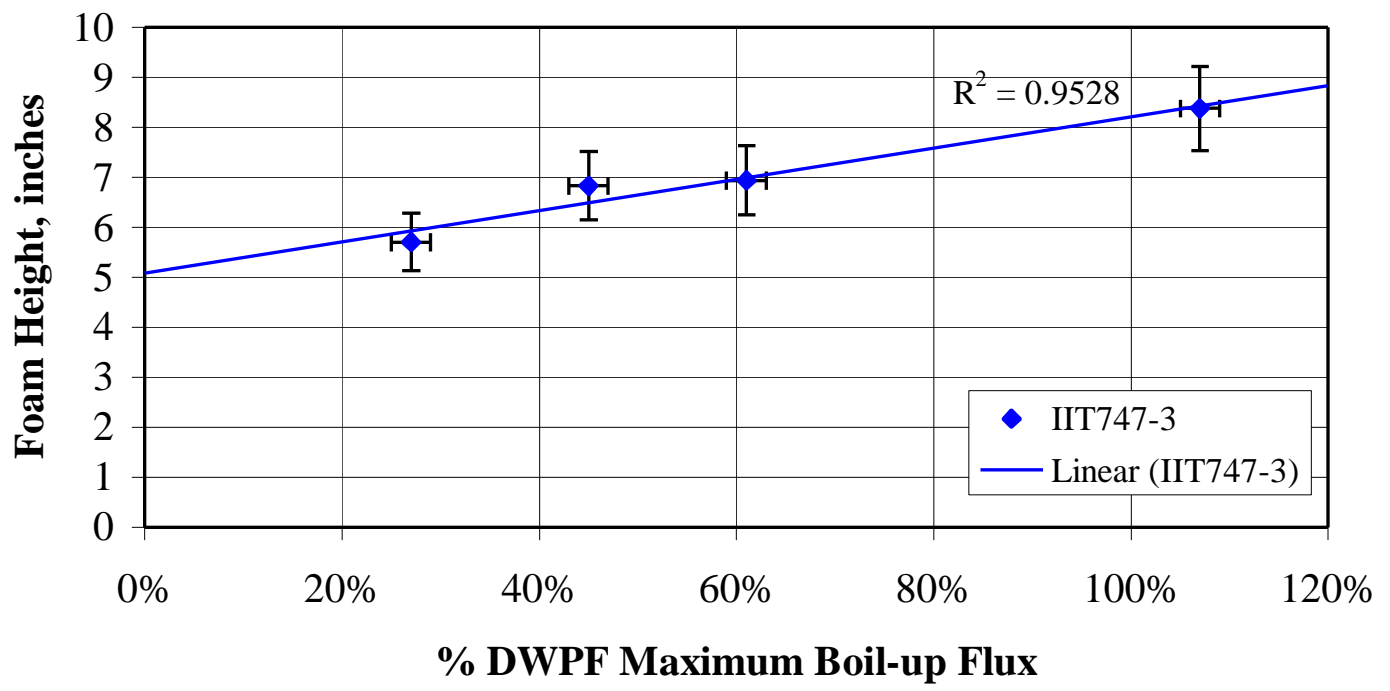


A thorough re-examination of the data for Foam Test \#3 was conducted in an attempt to explain the implied "added" foaminess, i.e. the foaminess at zero flux. No discrepancies in the analysis were found. Later water tests at the same liquid baseline showed negligible interaction with the upper SRAT impeller blade, which is about five inches below the vapor-liquid interface at $96^{\circ} \mathrm{C}$. Qualitatively the $26 \mathrm{wt}$. \% total solids foam was described as being more frothy and having larger bubbles (up to $1 / 2$-inch diameter). The bubbles showed less affinity for the vessel wall, making them harder to characterize. The SRAT side-walls had stayed much cleaner during the IIT747 antifoam test, and this enabled observations to be made of the entire top layer of the foam vs. just the foam near the walls. The foam layer was seen to be much more uneven (in the center) than at lower wt. \% total solids. It is possible that this unevenness was visually averaged differently each time foam height data was taken. Another phenomenon observed was that large drops of sludge slurry were being ejected from the top of the foam by up to 12 inches at the $107 \%$ boil-up flux, or about 20 inches above the baseline liquid level. Finer drops were entrained into the SRAT Condenser.

The SRAT Foam Test \#3 foam itself was quite different from the foam in all other SRAT and SME cycle foam tests, being fairly insensitive to boil-up flux without being shallow, i.e. one to three inches deep. Deep foams were very sensitive to boil-up flux in all other foam tests, and the shallow foams were comparatively insensitive to the boil-up flux. The SRAT Foam Test \#3 foams include the deepest observed foams at the 27\% of DWPF maximum boil-up flux plus some of the deepest foams observed during the IIT747 antifoam test.

Figure 10 presents the SRAT Foam Test \#3 foam heights in the same way that Figures 4 and 8 did for Foam Tests \#1 and \#2. DC544-5 was less foamy than DC544-2 and IIT747-5 was less foamy than IIT747-3. Antifoam ages were almost identical for DC544-2 and DC544-5. The antifoam for IIT747-5 was nearly six hours older than during IIT747-3. Consequently, the observed reductions in foaminess with increasing processing time were not likely to be due to the antifoam age. This would seem to indicate that the SRAT slurry became inherently less foamy as it was processed. A similar observation was made in IIT747-1B vs. IIT747-1A where the $27 \%$ and $61 \%$ fluxes were repeated after being shut down over night. Less foam was observed at both fluxes in the repeated tests.

The single piece of conflicting data came from SRAT Foam Test \#2 at $61 \%$ and $107 \%$ of the DWPF maximum boil-up flux during IIT747-2 and IIT747-4. Here the later test showed more foaminess than the earlier test. If this reversed difference was primarily due to increased antifoam age, then the more processed slurry of IIT747-4 might have been intrinsically less foamy than IIT747-2. Under this assumed hierarchy of effects, it might be prudent to increase the addition level and/or frequency for IIT747 antifoam versus Dow Corning 544 antifoam as currently practiced in DWPF. By the end of test IIT747-5, the antifoam had been in the SRAT for 10.5 hours, all at boiling. The SRAT appeared to be marginally foamier from the middle of the cycle to the end during the 
IIT747 antifoam test. In any case, it was clear that foaming was under control, i.e. less than one foot of foam, with either antifoam in all four tests in Foam Test \#3.

Figure 10. SRAT Foam Test \#3.

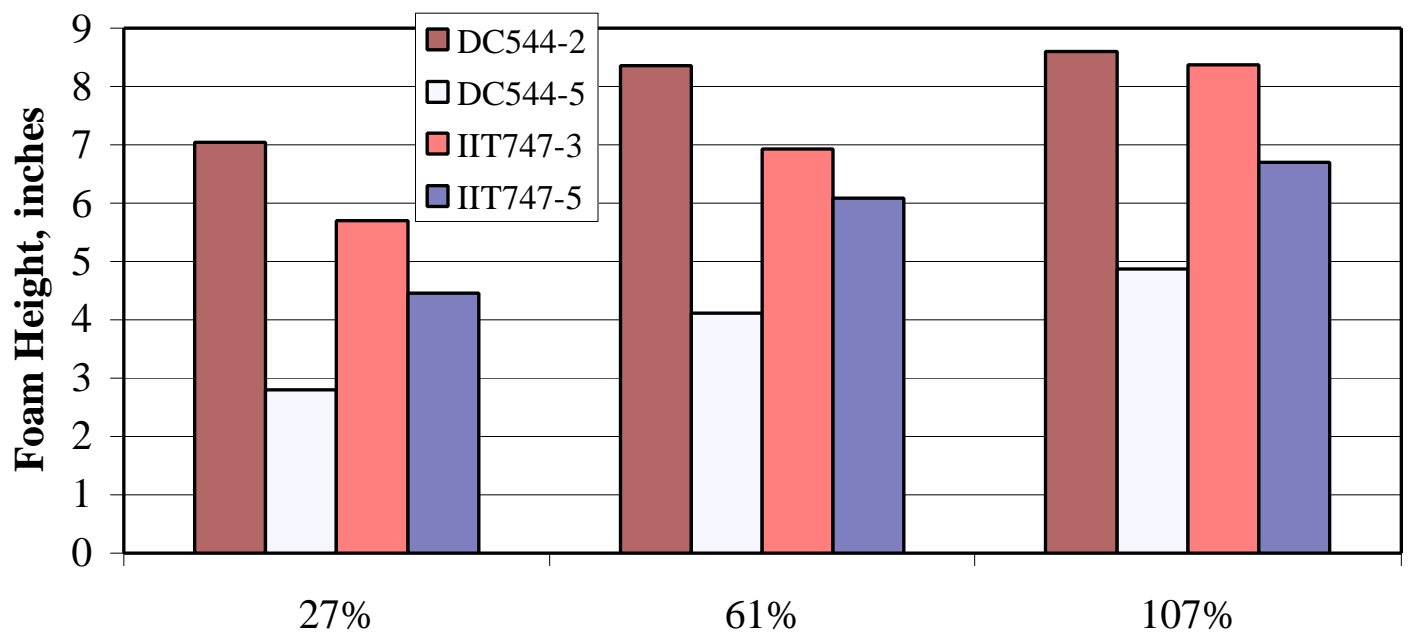

\% DWPF Maximum Boil-up Flux

\section{SRAT Foam Heights During Concentrations}

Based on findings from the pseudo-steady state foam tests, the analysis was extended into the periods of concentration that occurred between many of the tests discussed above.

The SRAT contents must transition from one set of foam heights and wt. \% total solids to another. This transition did not necessarily give a monotonic foam height as a function of wt. \% total solids.

It was possible to record the position of the top of the SRAT foam versus time as the SRAT contents were concentrated between the pseudo-steady state foam tests. It was not convenient, however, to stop boiling and take liquid baseline levels for each reading. Instead, data on SMECT level and SRAT steam coil flow were combined to calculate the reduction in mass of the SRAT contents corresponding to each foam height reading.

The necessary additional baseline liquid levels were interpolated from the nearest measured baseline levels based on the SRAT/SME mass change. Once a baseline level had been calculated, it was possible to determine a foam height. (It is worth mentioning that the bottom edge of the foam layer was never clearly defined, i.e. could not be recorded as data, even though that part of the system was visible. This was primarily due to the downward entrainment of small bubbles by the liquid draining from the collapsing bubble lamella at the top of the foam layer. These bubbles were visible both above and below the vicinity of the baseline liquid level measured at $96^{\circ} \mathrm{C}$.) 
SRAT concentrations generally occurred at about $27-75 \%$ of the DWPF maximum boilup flux. This relates to certain geometric differences between the GFPS and DWPF. The scaled DWPF maximum boil-up flux converted to $\mathrm{lb} / \mathrm{hr}$ and scaled by $1 / 240$ gives a GFPS boil-up flux of only $27 \%$ the DWPF maximum boil-up flux. The GFPS flux was kept down so that chemical and stripping processes would stay more or less synchronized with DWPF processing. Figure 11 shows data taken concentrating between the IIT747-1, IIT747-2 and IIT747-3 foam tests. Note that the system was refluxed for the duration of the IIT747-2 foam test, about one hour, in the middle of this plot. Most of the concentration was done at a boil-up flux of about $45 \%$ of the DWPF maximum. As can be seen in the figure, the foam height increased with increasing wt. $\%$ total solids until about $24 \mathrm{wt} . \%$. (Increasing foam height trends are also observed for the $27 \%, 61 \%$, and $107 \%$ flux data as wt. \% total solids increases using IIT747 antifoam.)

Figure 11. SRAT Foam Heights

(Tests IIT747-1 through IIT747-3)

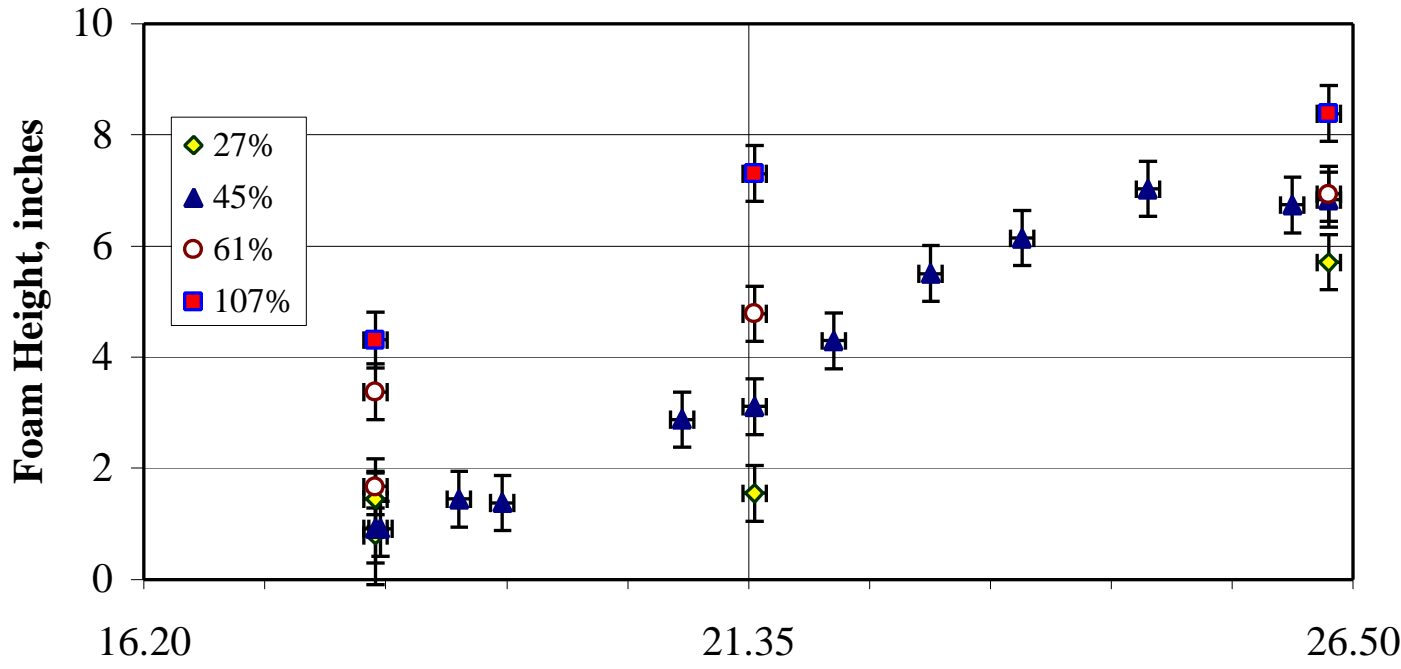

Wt. \% Total Solids

Following IIT747-3 (the right endpoint of Figure 11), the SRAT was diluted back to 21.3 wt. \% total solids with water. Foam Test IIT747-4 was run, followed by a concentration at $56 \%$ of the DWPF maximum boil-up flux to $26.5 \mathrm{wt}$. \% total solids. This data spanned part of the wt. \% total solids range given in Figure 11 above. Figure 12 compares the foam height results for these two concentration periods. Pseudo-steady state data at $61 \%$ flux was included with the $56 \%$ flux concentration data. 


\section{Figure 12. Comparison of SRAT Concentrations}

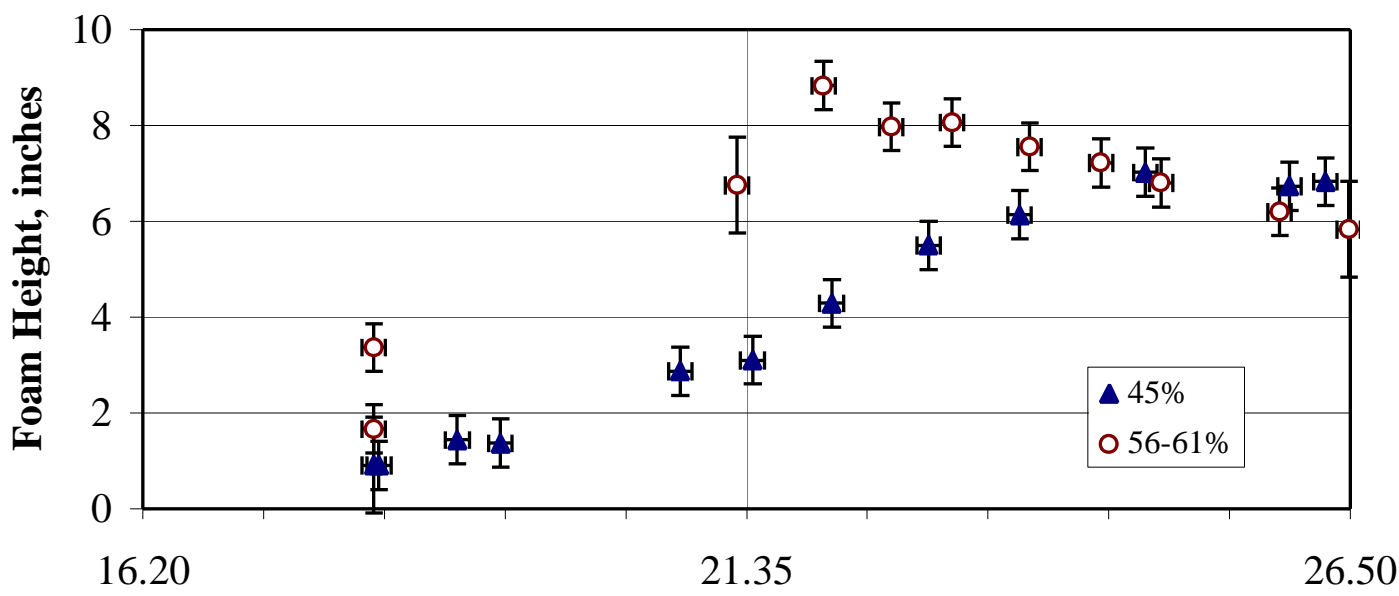

Wt. \% Total Solids

Observe in Figure 12 that foam height increased at $45 \%$ flux from $18 \mathrm{wt}$. \% total solids to around $24 \%$. For the higher flux, however, the maximum foam height occurred around 22 wt. \% total solids. Foam height then decreased with increasing wt. \% total solids until the concentration period ended at $26.5 \%$.

The shift in the position of maximum foam height as a function of wt. \% total solids, if reproducible, could be caused by several factors alone or in concert. The SRAT chemical reactions were certainly still ongoing between IIT747-1 and IIT747-3. Most of the measurable reactions had died down, however, by the end of IIT747-3 (starting point of the higher flux concentration period). The one exception was hydrogen evolution, but this was extremely small during the testing. Another explanation could be that the maximum foaminess shifts as a function of boil-up flux. Two data points was not really enough to be conclusive.

The natural place to look for supporting evidence would be in the Dow Corning 544 antifoam trials. The useful data from the initial concentrations following foam tests DC544-1A, DC544-1B, and DC544-1C is summarized below (see page 28). This data was not contradictory to what was said above, but it did not lend itself to a similar graphical presentation. (The boil-up flux was varied more frequently in the Dow Corning trial concentration periods. This provided more information on the effect of different fluxes on foam height at the expense of obtaining information comparable to that obtained in the IIT747 run on the effect of wt. \% total solids on foam height at constant flux.)

There were three other data sets that bear on the issue of a maximum in foaminess as a function of wt. \% total solids. Using Dow Corning 544 antifoam, the foam height at $107 \%$ of the DWPF maximum boil-up flux is less than 18 inches at $21.4 \mathrm{wt} \%$ and 
greater at $18.2 \mathrm{wt} . \%$. Since the foam height is taken as zero at $0 \mathrm{wt} . \%$ (supernate is nonfoaming), there must be a maximum in foam height on the interval 0-21.4 wt. \% at $107 \%$ flux when using Dow Corning 544 antifoam. This would seem to indicate a shift in the same direction as that indicated by the two sets of data in Figure 12.

As the SRAT was concentrated, diluted, and re-concentrated, the processing time continued to increase. A factor of potential relevance to the study of any temporal effects on foam height (beyond the chemical changes that were occurring) was particle agglomeration. As the SRAT was concentrated to $26.4 \mathrm{wt}$. \% total solids initially, a certain portion of the sludge solids were expected to agglomerate. Dilution does not automatically destroy agglomerates. The principal problem with this proposed mechanism as an explanation for the shift in the maximum above was that the foam heights from the IIT747-4 test were generally higher than from the IIT747-2 test, Figure 12 above. The opposite effect would be expected in the presence of a significant quantity of agglomerated solids (based on the IIT research).

In an attempt to resolve this issue, three samples were submitted for particle size analysis. These included the SRAT following acid addition (prior to IIT747-1), the SRAT at the time of IIT747-3, and the SRAT at the end of the cycle (after IIT747-5). The first and third showed no evidence of agglomeration, but the intermediate sample did show evidence of agglomeration. Perhaps $28 \%$ by volume of the sludge solids appeared to be incorporated into agglomerates. (Care was taken to shake the samples only sufficiently to slurry them in an attempt to not destroy any agglomerates mechanically.) By the time that it was decided to have these analyses made, the samples had various histories of previous analyses. It is not clear what effect the frequent mixing for aliquoting that occurred in some cases might have had on any agglomerates. This is the first time that particle sizes during the SRAT cycle were examined, and it might be worth doing this again with the intention of getting the samples analyzed at about the same time they are taken instead of two months later.

As mentioned above, there was also some foam height data from concentration periods with the Dow Corning 544 antifoam. The primary complicating factor in extracting useful information from these periods was that the boil-up flux was not kept constant over long periods the way it was during the IIT747 antifoam test (one competing goal was finding when the SRAT could be brought to the full DWPF boil-up flux, while still keeping the contents in the tank). Graphs similar to Figures 11 and 12, attempting to show this data, would be more confusing than helpful. Instead, some specific observations and conclusions will be listed:

1. Foam height increased with increasing wt. \% total solids over the range 18.2-19.5 at a boil-up flux of $27 \%$ of the DWPF maximum. A maximum in foam height versus wt. $\%$ total solids might exist at $>19.5 \mathrm{wt}$. \% total solids for this flux. 
2. Foam height increased with increasing wt. \% total solids over the range 18.2-20.4 at a boil-up flux of $45 \%$ of the DWPF maximum. A maximum in foam height versus wt. $\%$ total solids could exist at $>20.4$ wt. \% total solids for this flux.

3. Foam height increased with increasing wt. \% total solids over the range 19.5-20.5 at a boil-up flux of $61 \%$ of the DWPF maximum. A maximum in foam height versus wt. $\%$ total solids ought to exist at $>20.5 \mathrm{wt}$. \% total solids for this flux.

4. Foam height changed slowly with increasing wt. \% total solids over the range 22-24 at a boil-up flux of $50 \%$ of the DWPF maximum (observed twice). A maximum in foam height versus wt. \% total solids might exist near 22-24 wt. \% total solids for this flux.

5. Foam height changed slowly with increasing wt. \% total solids over the range 21-22.5 at a boil-up flux of $37 \%$ of the DWPF maximum. A maximum in foam height versus wt. \% total solids might exist near 21-22.5 wt. \% total solids for this flux.

6. Foam height decreased with increasing wt. \% total solids over the range 23.5-26.2 at a boil-up flux of $50 \%$ of the DWPF maximum. A maximum in foam height versus wt. $\%$ total solids probably exists at $<23.5 \mathrm{wt}$. \% total solids for this flux.

These observations were compiled from the first concentration period following the initial foam test in each of the three GFPS runs using Dow Corning 544 antifoam, i.e. after DC544-1A, DC544-1B, and DC544-1C. Foam heights at fluxes in excess of $60 \%$ of the DWPF maximum could not be studied at 18.2-20 wt. \% total solids, because these systems were so foamy that the SRAT would have foamed over. An exception was the run with size-reduced CST, which was less foamy initially than the other two runs. Unfortunately, the significance of this opportunity was not recognized at the time.

A last minute change in the run plan caused DC544-2, the first antifoam test following DC544-1A, to come at $27.0 \mathrm{wt}$. \% total solids (rather than 21\%). In comparing Figure 4 data for DC544-1A, B, C and Figure 10 data for DC544-2, some interesting things will be noted. At $27 \%$ of the DWPF maximum boil-up flux, the foam height has increased from 3-3.5 inches to 7 inches upon concentration. At $61 \%$ of the maximum DWPF boil-up flux, the foam height has decreased from 10-17+ inches to 8 inches upon concentration. At no time in these experiments was foam height observed to increase as boil-up flux decreased at constant wt. \% total solids. There were one or two instances, however, where increasing the boil-up flux did not appear to cause a detectable increase in the foam height. This could occur if the system was at a wt. \% total solids concentration inbetween two maxima as a function of boil-up flux, i.e. on the down-side for one flux and the up-side for the other. As discussed above, there is strongly suggestive evidence that the wt. \% total solids giving maximum foaminess in the simulant system does depend on the boil-up flux. The evidence here was stronger than that in the IIT test data discussed in the Background section. 
Complicating the above observations and analyses are some process issues that need to be brought to the attention of the unwary reader. The act of sampling the SRAT often had a profound effect on the foam height. The GFPS SRAT was not visually homogeneous from top to bottom, i.e. was not uniformly mixed. Sampling involved circulating slurry from the bottom of the SRAT through a pump and back onto the vaporliquid interface in the SRAT. Consequently, this process could remix the tank partially, and it could also either transport antifoam that had collected at the vapor-liquid interface back into the bulk tank contents or replenish surface antifoam from the bulk dissolved antifoam reservoir.

Two examples of this in the foam height data are given here to illustrate the effect. At $37 \%$ of the DWPF maximum boil-up flux, foam height was running at 11.5-15 inches at 18.5-19 wt. \% total solids (four data points). A sample was taken per a two hour sampling schedule. Following sampling, the foam height was about 7 inches (two data points). A nearly identical observation in the same wt. \% total solids range from another trial went in the exact opposite direction, where 3-4 inches of foam increased to 6-7 inches after sampling at $27 \%$ of the maximum DWPF boil-up flux.

During the IIT747 antifoam test, most sampling was done immediately following a pseudo-steady state test or at the time a baseline liquid level was established, instead of during the concentration period. That is probably one reason why Figures 11 and 12, given for the IIT747 test above, show relatively well-behaved foam height behavior. Since DWPF does not generally sample in the middle of the SRAT cycle, they do not normally have to worry about such things. However, DWPF should be cautioned to avoid sampling in the middle of the SRAT cycle without giving serious thought to adding additional antifoam.

It was never claimed that this study could quantitatively elucidate all of the fundamental factors affecting foaming in the SRAT. Even if there had been enough data to give a plot of wt. \% total solids at maximum foaminess versus boil-up flux, it would not necessarily apply to the real DWPF waste. There will always be differences in rheology, particle size, composition, etc. that limit the extent to which the simulant system can mimic the real system. Additional testing could be performed on the samples that were archived from these two antifoam comparison runs.

\section{SME Foam Tests}

Foam tests in the SME cycle were conducted after the first frit addition, after concentration following the first frit addition, and after the second frit addition. Some additional data was obtained at the end of the SME cycle during the IIT747 antifoam test. Foaming was effectively controlled by $100 \mathrm{ppm}$ levels of both antifoams during the SME cycle. Foam heights rarely exceeded three inches.

The total solids concentration in the SME following the first frit addition was about $28 \%$. Antifoam was added after this frit addition in both runs. Foam tests DC544-6 and IIT747-6 were performed here. Figure 13 presents the foam height data at 27\%, 61\%, 
and $107 \%$ of the DWPF maximum boil-up flux. The total solids content in these two tests is very similar to the solids concentration in SRAT Foam Test \#3. The system volume is quite a bit larger, however, about $41 \%$ more by mass, following frit addition. The nature of the solids also changes dramatically once frit is added. The solids are larger on average and the ratio of soluble to insoluble solids falls once frit is added. This combination of factors led to a significant reduction in observed foam height at all fluxes versus SRAT Foam Test \#3.

Figure 13. First SME Foam Test.

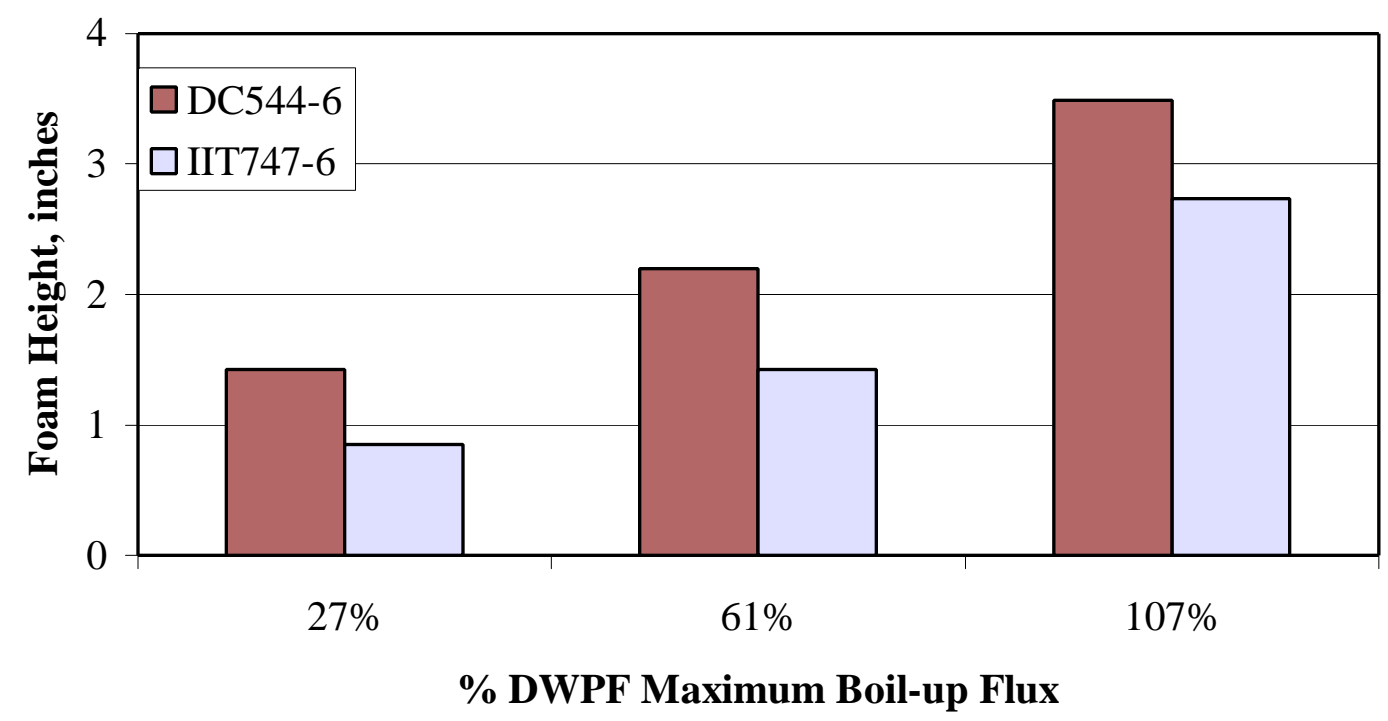

After the first SME Foam Test, the SME was concentrated to a total solids concentration of about 39\%. Foam tests DC544-7 and IIT747-7 were performed. Since the net composition of the frit-water-formic acid slurry was about $35 \mathrm{wt}$. \% total solids, the total solids concentration only dropped to about $38 \%$, after making the second frit addition. Foam tests DC544-8 and IIT747-8 were then performed.

Figure 14 presents the results from both pairs of foam tests at 38-39 wt. \% total solids (before and after adding the second half of the frit slurry). Foaming was being effectively controlled in all tests. Minimum uncertainty in the foam height calculation should be taken as about \pm 0.5 inches when comparing between different tests (due to inherent problems in determining the baseline liquid level). Within a given test at three fluxes, the uncertainty in comparing was much less, however, since all foam heights assumed the same baseline position. Consequently, it is legitimate to say the foam height increased with increasing flux. It is not legitimate to say that DC544-8 had more foam then DC544-7 at $61 \%$ flux. The $1 / 4$-inch difference is too uncertain.

IIT747-9 tested foaming at the end of the SME cycle at $61 \%$ and $107 \%$ at about $47 \mathrm{wt}$ \% total solids. Foam heights were 1.1 and 2.3 inches respectively, i.e. similar to the other SME data with IIT747 antifoam. Concentration data between SME pseudo-steady state 
foam tests showed a lot of noise, but regressed with small negative slopes suggesting that the foam height was decreasing with increasing wt. \% total solids and/or processing time.

Figure 14. SME Foam Tests at $\sim 39$ wt. \% Solids

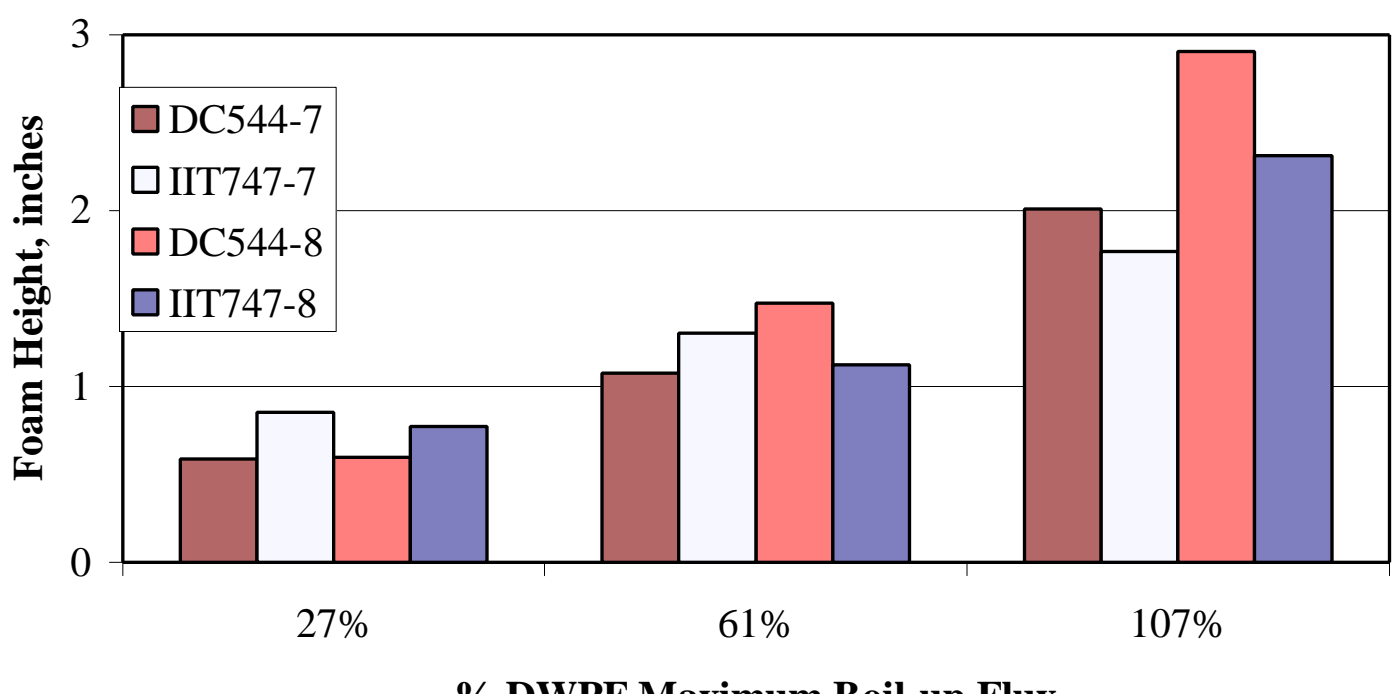

The second frit addition during the IIT747 antifoam run was made on a Friday just before shutting down for the weekend. On the following Monday, the SME was brought to boiling without adding antifoam. Total elapsed time from the most recent antifoam addition was 71 hours, of which about five hours were at boiling, and at least 64 hours were at less than $50^{\circ} \mathrm{C}$. Test IIT747-8 was started at $27 \%$ of the DWPF maximum boil-up flux. The foam steadied out about 1.5 inches above the baseline liquid level. When the boil-up flux was raised to $61 \%$, the foam height increased to about 14 inches (about eight inches below the lid of the vessel). It was judged that the slurry would foam over before reaching $107 \%$ of the DWPF maximum boil-up flux. The IIT747 antifoam had apparently lost its effectiveness. After twenty minutes at $61 \%$ flux, a fresh addition of IIT747 antifoam was made. The foam immediately collapsed to a height of only 1.1 inches. This level was held for twenty minutes at which time the boil-up flux was increased to $107 \%$ for twenty minutes, and test IIT747-8 was completed. This experience confirmed the foaming potential of the SME simulant formulation, showed that IIT747 antifoam had a limited service life in the SME cycle, and showed that IIT747 was effective in collapsing SME foam after it had been formed.

\section{Quantitative Observations -- SRAT/SME Chemistry During Antifoam Testing}

The TTP for the antifoam comparison experiments included a study of the dependence of foaminess on processing conditions such as $\mathrm{H}_{2}$ generation, the $\mathrm{CO}_{2}$ peak, the $\mathrm{N}_{2} \mathrm{O}$ peak, and the inferred $\mathrm{NO}_{\mathrm{x}}$ peak, as well as an analysis of the nitrite anion destruction rate and the mercury removal efficiency relative to mass of steam stripped from the SRAT. $\mathrm{N}_{2} \mathrm{O}$, 
$\mathrm{NO}_{\mathrm{x}}$, and nitrite anion destruction will be covered under Nitrogen Species below, mercury removal under Mercury below, and $\mathrm{H}_{2}$ and $\mathrm{CO}_{2}$ under Other Gas Evolution Effects below. Additionally, DWPF requested information on the impact of antifoam on glass chemistry and an estimate on the effect of a switch on downstream vapor processing equipment. These issues will be discussed under Antifoam Chemistry.

Gas fluxes observed during any of the FY99 GFPS trials were much smaller than the boil-up fluxes. Detection of any gas above a $10 \%$ concentration in the FAVC outlet was rare. A $10 \%$ concentration of either $\mathrm{CO}_{2}$ or $\mathrm{N}_{2} \mathrm{O}$ corresponds to a flux of $0.48 \mathrm{lb} / \mathrm{hr} / \mathrm{ft}^{2}$, or $1.1 \%$ of the DWPF maximum boil-up flux in the SRAT cycle. All gas compositions are in molar, or volume, $\%$.

\section{Nitrogen Species}

The mass of nitrite anion in the simulant slurry was reduced by two orders of magnitude during the two GFPS SRAT cycles. The initial nitrite concentration was about 6200 $\mu \mathrm{g} / \mathrm{mL}$. The concentration at the end of the Dow Corning 544 antifoam SRAT cycle was $56 \mu \mathrm{g} / \mathrm{mL}$. This represented a decrease from about 680 grams to 4.2 grams of nitrite anion (163 kg to $1 \mathrm{~kg}$ at DWPF-scale). The nitrite concentration at the end of the IIT747 antifoam SRAT cycle was $86 \mu \mathrm{g} / \mathrm{mL}$. This represented a decrease from about 680 grams to 6.5 grams (163 kg to $1.5 \mathrm{~kg}$ at DWPF-scale). Note: the IIT747 antifoam SRAT cycle was shorter than the Dow Corning 544 SRAT cycle in time, but equivalent in pounds of steam evaporated. Nitrite ion concentrations at the end of the SME cycle were reported as $<100 \mathrm{ppm}$ and $<91 \mathrm{ppm}$ for the Dow Corning 544 and IIT747 antifoam tests respectively.

A pseudo-first order rate constant was derived for nitrite ion decomposition during the middle and end of the SRAT cycle. A value of $0.0049 \pm 0.0001 /$ minute was obtained for both runs. The corresponding half-life of nitrite ion was about $141 \pm 2$ minutes. This was supporting evidence that the two runs were comparably batched with sludge and acids. The rate of nitrite ion decomposition was known to also be a strong function of the per cent excess acid used in the SRAT cycle. Half-lives one-tenth as large as this have been observed in some bench-scale SRAT runs with higher excess acid.

Nitrate concentration, or at least nitrate mass, was expected to increase during the SRAT cycle. One basis of the CPC acid calculation is that about $35 \%$ of the destroyed nitrite ion will appear as nitrate ion. This must surely depend on whether or not the SRAT was being either refluxed or concentrated at the time that most $\mathrm{NO} / \mathrm{NO}_{2}$ was being condensed in the SRAT condenser. Because of the demands of foam testing and days-only operation, the typical DWPF SRAT cycle was not followed exactly. A precise interpretation of the SRAT nitrate ion data was difficult for a number of reasons that will not be elaborated on. It appears that somewhere between $10 \%$ and $30 \%$ of the nitrite ion ended up as nitrate ion in the SRAT product. Additional nitrate ion appeared in the MWWT, see below, and potentially appeared also in the SMECT. The SMECT was charged with dilute nitric acid at the start of each run, making detection of small changes in total nitrate ion there more challenging than the available funding allowed (averaging 
of many multiple sample sets would have been required to obtain the necessary statistical confidence).

The GC monitoring the FAVC exit gas was sensitive to $\mathrm{N}_{2} \mathrm{O}$. Additionally, the ratio of $\mathrm{N}_{2} / \mathrm{O}_{2}$ is interpreted as being sensitive to consumption of oxygen by $\mathrm{NO}$ to produce $\mathrm{NO}_{2}$, $\mathrm{N}_{2} \mathrm{O}_{5}$, etc. The GFPS equipment arrangement provided a number of poorly mixed volumes and lengths of pipe in addition to the vapor spaces in the SRAT and SMECT where gases could be accumulated or depleted as a function of time. One finding of this study was that performing foaming tests at different boil-up fluxes was not conducive to obtaining smooth concentration versus time traces from the GC. A jump in steam flow would produce a reduced residence time in the SRAT and SRAT condenser. This would produce a spike in the composition measurements of gases being evolved in the SRAT. Different problems were observed during formic acid addition. There was some trouble with that acid addition pump, and two changes were made to it during the formic acid addition step for the IIT747 antifoam run. Corresponding to these pump changes were small dips in the concentrations of the gases being evolved during the formic acid addition step of the SRAT cycle.

The maximum $\mathrm{N}_{2} \mathrm{O}$ evolution rate was obtained near the end of formic acid addition. It continued into the subsequent water flush of the formic acid carboy and on into the ramp of temperature from $93^{\circ} \mathrm{C}$ to $100^{\circ} \mathrm{C}$. About 36 grams of $\mathrm{N}_{2} \mathrm{O}$ were evolved in the IIT747 test run. This was equivalent to 75 grams of $\mathrm{NO}_{2}{ }^{-}$destroyed based on identical moles of nitrogen exchanged (18 kg at DWPF-scale), or about $11 \%$ of the initial nitrite charge.

After the one hour IIT747-1A foam test, during which no $\mathrm{N}_{2} \mathrm{O}$ was detected, the system was shut down for the day. When the system was brought to boiling the next day, there was a further release of $\mathrm{N}_{2} \mathrm{O}$ at about one-tenth the gas concentration above but for about three times as long. This coincided with a foaming episode in the SRAT. Antifoam had not been added since the previous day. Once antifoam was added, the foam was effectively destroyed.

Brief jumps in $\mathrm{N}_{2} \mathrm{O}$ concentration during the testing were related to process upsets such as sampling (running the recirculation pump) and shutting off steam to get a baseline level for a foam test. $\mathrm{N}_{2} \mathrm{O}$ concentration dropped below the sensitivity of the GC during the second foam test. $\mathrm{N}_{2} \mathrm{O}$ was only detected once more, and then only briefly, following the IIT747-2 foam tests (during sampling). This observed behavior may be an indicator of inadequate mixing in the GFPS SRAT. Both switching from non-boiling to boiling and running the recirculation pump increase the degree of mixing in the SRAT. This could be expected to produce momentary surges in reaction rates.

The SMECT was analyzed for ammonium ion during both antifoam test runs. The ammonium ion concentration remained below the detection limit of $10 \mu \mathrm{g} / \mathrm{mL}$ during both runs. Apparently this was not an important factor in the nitrogen balance at the present time. 
The MWWT was charged with water at the beginning of each run. As time passed the liquid increased in concentration of nitrite, nitrate, mercury, etc. coming from the SRAT condenser. The GFPS MWWT is disproportionately large compared to the DWPF MWWT. It holds about $14.3 \mathrm{~kg}$ (3420 kg at DWPF-scale, or about 900 gallons).

The ratio of $\mathrm{N}_{2} / \mathrm{O}_{2}$ ratio was about 3.6 for the IIT747 antifoam test except from the middle of formic acid addition to the end of the IIT747-2 foam test (about eight hours). The ratio rose to 4.05 near the end of the formic acid addition period and rose briefly to 4.4 as the SRAT went to boiling at $27 \%$ of the DWPF maximum boil-up flux for foam test IIT747-1A. The ratio then appeared to be decaying back to 3.6 over the next five hours of processing. There were brief spikes associated with any increases in steam flow, as well as dips associated with cuts in steam flow. When the boil-up flux was cut from $107 \%$ to $45 \%$ following the high flux segment of the second SRAT foam test, the ratio returned to its starting value, where it remained for the duration of the SRAT and SME cycles (within the noise of the GC measurement data).

Similarly, the ratio of $\mathrm{N}_{2} / \mathrm{O}_{2}$ ratio was about 3.55 for the Dow Corning 544 antifoam test except from the middle of formic acid addition to the end of the DC544-2 foam test (again about eight hours). The ratio rose to 3.9 near the end of the formic acid addition period and rose briefly to 4.35 as the SRAT first went to boiling at $27 \%$ of the DWPF maximum boil-up flux. The ratio then appeared to be decaying back to 3.55 over the next six hours of processing. The data was qualitatively similar to that obtained during the IIT747 antifoam test. Both sets of data were noisy.

The $\mathrm{N}_{2} / \mathrm{O}_{2}$ ratio is believed to be related to the formation of $\mathrm{NO}_{\mathrm{x}}$ species. The precise reaction pathways and their relative importance have not been reported. The maximum ratio of 4.4 could be explained by a drop in $\mathrm{O}_{2}$ from $21 \%$ to $17.2 \%$. If all the lost $\mathrm{O}_{2}$ was assumed to combine with $\mathrm{NO}$ to make $\mathrm{NO}_{2}$, this would translate into a maximum composition of $\mathrm{NO}_{2}$ of $7.6 \%$ (downstream of the FAVC basis). In both test runs the maximum value of the $\mathrm{N}_{2} / \mathrm{O}_{2}$ ratio occurred when the system was first brought to boiling. From the available data it appears that perhaps half of the spike was a dynamic phenomenon associated with the rapid displacement of accumulated gases in the SRAT vapor space by steam, and the other half was due to on-going generation. Although much of any $\mathrm{NO}_{2}$ actually formed in the SRAT should react/condense with water in the SRAT Condenser to make nitric acid, this does not affect the calculation, which infers the presence of $\mathrm{NO}_{2}$ by the absence of $\mathrm{O}_{2}$. The implied high gas generation rates early in the SRAT cycle boiling period provide a parallel nucleation path for bubbles with boiling itself. Although the evolved gas mass flux was probably much lower than the boil-up flux, the gas bubbles evolved from chemical reactions were probably smaller and more numerous and could have negatively impacted foaming. The available data suggest that this phenomena was limited to about the first four hours of the SRAT cycle for the processing conditions studied here. 


\section{Mercury}

The SRAT was charged with $188.6 \mathrm{~g}$ of mercury in the form of $\mathrm{HgO}$ prior to both antifoam test runs (and both CST runs). Mercury oxide appeared to reduce quickly to elemental mercury during formic acid addition at $93^{\circ} \mathrm{C}$ in the SRAT cycle. A gray film formed on top of the SRAT contents near the end of formic acid addition. This film is believed to be enriched in mercury. See Figure 15 below. Colloidal mercury droplets could easily enhance the foaminess of the SRAT, and there is now further visual evidence that something is present. The marked superiority of the IIT747 antifoam to the Dow Corning antifoam, when the SRAT first goes to boiling, may be due to differences in their relative effectiveness in mitigating a mercury-rich foam (rather than a sludge-rich foam).

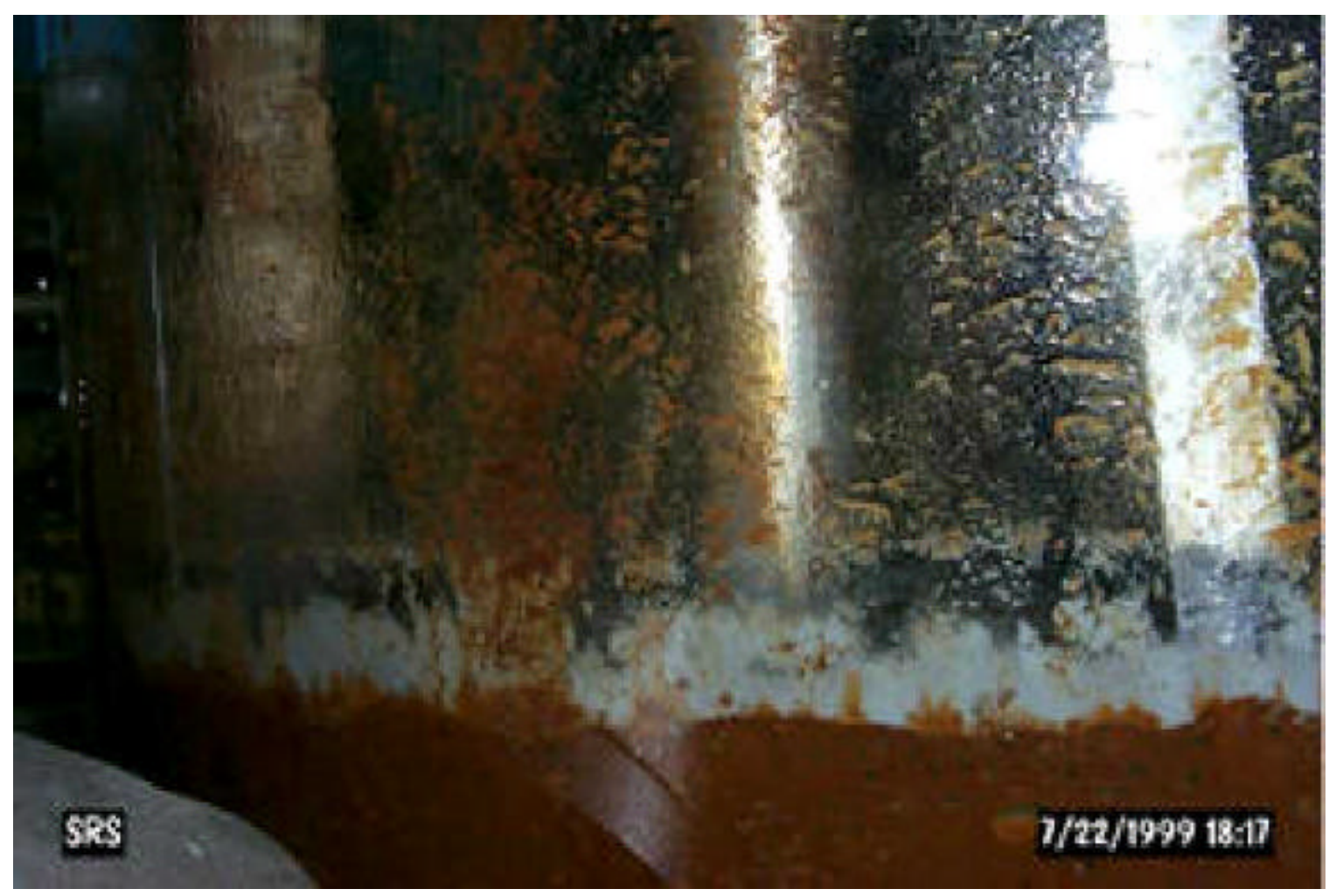

Figure 15. Side-view of the SRAT Vapor-Liquid Interface Showing the Gray Film (at $27 \%$ of DWPF Maximum Boil-up Flux with Dow Corning 544 Antifoam at 18.2 wt. \% Total Solids).

There were about $51 \mathrm{~g}$ of $\mathrm{Hg}$ left in the SRAT at the end of the Dow Corning 544 test run versus about $58 \mathrm{~g}$ in the IIT747 test run (73\% and 69\% removal efficiency). Removal factors in pounds water stripped per pound mercury stripped were about 1860 and 1680 respectively for the Dow Corning 544 test and IIT747 test. These numbers were two to three times higher than accepted value of $750 \mathrm{lb} \mathrm{steam} / \mathrm{lb} \mathrm{Hg}$. (This phenomena was also observed in the two CST foam study batches.) Because of the nature of the foaming 
experimental test plan (concentrate-dilute-re-concentrate), more condensate was actually put to the SMECT relative to the MWWT during the SRAT cycle than in a typical DWPF SRAT cycle (single concentration). A lower removal factor might have been expected for this reason, but higher removal factors were observed instead.

There were about $19 \mathrm{~g}$ of mercury left in the SME at the end of the Dow Corning 544 test run versus about $28 \mathrm{~g}$ in the IIT747 test. Overall, about $85-90 \%$ of the mercury was successfully stripped (versus recycled) prior to the end of the SME cycle. About 165 grams of mercury should be found elsewhere in the process each run. Mercury could accumulate in the SRAT, in the MWWT, in the SMECT, in the FAVC seal loop drain leg, in the SRAT Condenser heads and tubes, in the FAVC heads and tubes, and in the piping. A small amount of mercury was vented to the atmosphere. The rest of this section describes what was learned about the fate of the stripped mercury.

Following a SRAT/SME run (recall that one vessel is used for both cycles), one or more small droplets of elemental mercury were occasionally observed during vessel cleaning operations. This would be reduced mercury that failed to transfer with the SME product slurry into the receipt drum. A small amount of contaminated elemental mercury was obtained from the MWWT drain each run ( $<5$ grams each run). Other than some black solids deposited on the tube walls of the SRAT Condenser, nothing else was observed that appeared to contain elemental mercury as a separate phase. The amount of mercury dissolved in the aqueous phase in the MWWT was about $490 \mathrm{mg} / \mathrm{liter}$ or 7 grams by the end of the SRAT/SME cycle.

The analyses of SMECT liquid samples were erratic in mercury content (30-160 ppm), but suggest an upper bound of 20 grams of dissolved mercury collected in the SMECT condensate each run (or $5 \mathrm{~kg} /(\mathrm{SRAT} / \mathrm{SME}$ batch pair) at DWPF-scale). The SMECT sample analyses are well below the solubility limit of mercury (as mercury oxide) in nitric acid solutions such as was present in the SMECT, however the acidity of the SMECT liquid is probably too low to oxidize elemental mercury at an appreciable rate. There were a number of consecutive data point pairs, however, that suggested that the mass of mercury in the SMECT was falling. The mass of mercury was either expected to rise or remain constant, depending on whether the SRAT/SME was being concentrated or refluxed. This may indicate some problems with sampling or the analytical method. It is quite possible that elemental mercury was collecting in the SMECT recirculation piping low points where it can't be seen (possibly including the sample point).

SRAT cycle loss of mercury into the purge gas was estimated to be about 0.5 grams over twelve hours at $26^{\circ} \mathrm{C}$. Cooling to $10^{\circ} \mathrm{C}$ should reduce this by a factor of four, but older data suggests that mercury is supersaturated in the gas leaving the FAVC to about four times the concentration predicted by its vapor pressure.

The GFPS glass SRAT Condenser is not vertical. It is only about $6^{\circ}$ off of horizontal. The SRAT Condenser inlet head had a puddle in it caused by the position of the lowest tube in the tube sheet relative to the lowest point in the inlet head. This puddle appeared 
to contain sludge that has been entrained in the vapor leaving the SRAT at high boil-up rates. (This entrainment could be observed visually, since the piping between the SRAT and the SRAT Condenser is glass.) The puddle was light gray with brown edges, suggesting it may contain some mercury mixed with sludge. The SRAT Condenser outlet head appeared to be clean and free of mercury. The SRAT Condenser tubes had dark solids stuck to the tube walls that were not believed to be sludge. (A given tube might have two or three globs along its 42 -inch length.) Presumably this material was contaminated mercury condensed in the SRAT Condenser. The impurities appeared to keep the mercury from flowing freely down the tubes. The quantity of trapped solids did not appear overly large after four runs in the GFPS at Tank 42 levels of mercury. The quantity was clearly increasing with number of runs. It was hard to imagine that there might be close to 500 grams of mercury in the SRAT Condenser however.

The inlet and outlet heads of the FAVC appeared to be free of mercury. The tubes cannot be seen because of the insulation currently wrapped around the shell. The FAVC condensate leg was drained after the SRAT cycle and after the SME cycle of both test runs. Mercury was detected in all samples during the antifoam testing (and also in similar samples taken during CST testing). Unfortunately, the total mass of condensate produced during either the SRAT or SME cycle from the FAVC was unknown. The condensate was continuously drained into the SMECT except for about one liter that helped form a seal loop. The table below summarizes the results:

Table IV. Mercury Content of FAVC Condensate

\begin{tabular}{|l|l|l|}
\hline & Dow Corning 544 Test & IIT747 Test \\
\hline After the SRAT cycle & $373 \mathrm{ppm}$ & $63 \mathrm{ppm}$ \\
\hline After the SME cycle & $71 \mathrm{ppm}$ & $272 \mathrm{ppm}$ \\
\hline
\end{tabular}

For comparison, results during the CST testing ranged from 200-500 ppm. Three points should be kept in mind when looking at these numbers. One, there was no forced agitation anywhere in this part of the process; two, the FAVC seal loop may not have been totally drained after each cycle of each test run; and, three, the condensate flow rate was so small that it was not visible to the naked eye. The numbers imply that there must be between 0.1 and 1.0 grams of mercury dissolved in the condensate contained in the FAVC seal loop.

Summarizing, of 188 grams of mercury charged, about 25 grams remained in the melter feed product, about 7 grams were collected in the MWWT aqueous phase and about 5 grams were collected as dirty elemental mercury, about 20 grams were collected in the SMECT, about 1 gram was collected in the FAVC condensate leg, and about 2 grams were lost to the atmosphere. Therefore, about two-thirds of the mercury was unaccounted for by material balance. Analysis of process waste stream drums supported this loss, i.e. the accumulated waste (SMECT condensate, MWWT liquid, SRAT flush water, etc.) was very low in mercury, as expected by the results for the individual sources. 


\section{Other Gas Evolution Effects}

The GC on the FAVC outlet line was sensitive to hydrogen and carbon dioxide in addition to the other gases discussed in the sub-section on nitrogen species above. Based on the marginal nitrite destruction reported above, it appeared that acid was not overadded. Over-adding acid had been linked to higher rates of hydrogen evolution. The process simulations were also conducted with $110 \%$ of Tank 42 levels of noble metals which were well below the maximums expected during the operational life of DWPF. Under these conditions little hydrogen generation was expected, and little hydrogen generation was observed.

More hydrogen generation was observed near the end of the Dow Corning 544 antifoam test run (14.7 hours of boiling in the SRAT) then in the IIT747 antifoam test run (10.8 hours of boiling in the SRAT). During the IIT747 test SRAT cycle, the hydrogen concentration never exceeded $0.001 \%$, the detection threshold for the GC, although there were sustained periods where this reading was obtained. Hydrogen concentrations as high as $0.005 \%$ were observed briefly in the Dow Corning 544 antifoam test about 3.5 hours before the end of the SRAT cycle. Concentrations of $0.002 \%$ were much more frequent than $0.001 \%$ from then until the end of the SRAT cycle. The maximum hydrogen concentration observed is equivalent to $0.0046 \mathrm{lb} / \mathrm{hr}$ of hydrogen in a 6000 gallon DWPF SRAT batch. Hydrogen remained significantly below the DWPF design basis of $0.65 \mathrm{lb} / \mathrm{hr}$.

The maximum hydrogen concentration observed during the SME cycle of the Dow Corning 544 antifoam test was $0.020 \%$. The purge gas flows during the SME cycle (as measured at the FAVC outlet) are less than half as large as during the SRAT cycle. This corresponds to $0.0084 \mathrm{lb} / \mathrm{hr}$ in a 6000 gallon DWPF SME batch. Hydrogen remained significantly below the DWPF design basis of $0.23 \mathrm{lb} / \mathrm{hr}$. The maximum hydrogen concentration observed during the SME cycle of the IIT747 antifoam test was $0.006 \%$. This was at the same purge gas flow.

\section{Antifoam Chemistry}

Dow Corning 544 antifoam is a solution of many components, six of which are present in excess of one weight per cent, see Table V below. Four of these main "components" are actually polymeric species with ranges of molecular weights and with various structures due to random side chain placements. The six main components are all formed from just four elements: carbon, hydrogen, oxygen, and silicon. Silicon atoms constitute 15\%-16\% of the Dow Corning 544 antifoam mass. One 100 ppm antifoam addition contributes approximately $0.0002 \%$ of the total silicon in glass at a basis of $35 \%$ waste loading. This is well within the uncertainty of the silicon mass in the frit addition. The basis for this calculation was the following composition for Dow Corning 544 antifoam, Table V. 
Table V. Partial Composition of Dow Corning 544 Antifoam

\begin{tabular}{|l|c|}
\hline Species: & Weight \\
\hline $\begin{array}{l}\text { Dimethyl, methyl (propylpolyethylene oxide, polypropylene } \\
\text { oxide, acetate) siloxane }\end{array}$ & $38 \%$ \\
\hline Poly (ethylene oxide propylene oxide) monoallyl ether acetate & $26 \%$ \\
\hline Dimethyl siloxane, hydroxy terminated & $15 \%$ \\
\hline Polydimethylsiloxane & $13 \%$ \\
\hline Polyether polyol acetate & $6 \%$ \\
\hline Treated amorphous silica & $2 \%$ \\
\hline D5 (cyclic dimethyl siloxane) material & $0.1 \%$ \\
\hline
\end{tabular}

IIT747 antifoam is a solution of up to four compounds. The composition is still proprietary, but some aspects of its chemical nature can be discussed. Three of the four components in IIT747 antifoam are polymeric in nature. The principal component (90\%) has a molecular weight of about 550-650. The secondary component (9\%) has a molecular weight of about 730-830. These two components are chemically similar to each other, except for the length of an internal $-\left(\mathrm{OCH}_{2} \mathrm{CH}_{2}\right)^{-}$, or polyethylene oxide, chain. Both components have chemical similarities to the two compounds that comprise $38 \%$ and $26 \%$ of Dow Corning 544 antifoam, which also contain polyethylene oxide chains. The two major components of IIT747 antifoam are trimethyl siloxy terminated, which makes them somewhat similar to the polydimethylsiloxane species in Dow Corning 544 antifoam.

The third component (1\%) in IIT747 antifoam has an average molecular weight of about 4000. It contains a polypropylene oxide section similar to one of the side chains in the major Dow Corning 544 antifoam component. The fourth component $\left(10^{-3}-10^{-5} \%\right)$ is an optional blue dye (methylene blue). The overall elemental composition of IIT747 antifoam as reported by IIT was $11.7 \%-15.1 \%$ silicon, $25.4 \%-30.4 \%$ oxygen, $44.4 \%$ $54.6 \%$ carbon, and 7.1\%-11.3\% hydrogen. One 100 ppm addition of IIT747 antifoam contributes slightly less to the total silicon mass in glass compared to Dow Corning 544 antifoam. It appears that a switch from Dow Corning 544 antifoam to IIT747 antifoam would have a negligible effect on glass chemistry.

The ether linkages, -CHR-O-CHR'- with R, R' being $\mathrm{H}$ or $\mathrm{CH}_{3}$, common to the polyethylene oxide, polypropylene oxide, and poly (ethylene oxide propylene oxide) chains in both antifoams are considered likely sites for attack and cleavage by acids under sufficiently vigorous conditions. It appears that washed sludge simulant, SRAT process simulant, and SME process simulant at room temperature may constitute sufficiently vigorous conditions to appreciably attack both the antifoams, or at least the key components of the two antifoams. Stripping of the decomposition products can be assumed to occur. 


\section{Suggestions for Improving the Experiment}

It appears that a pseudo-steady state foam height can be obtained in five minutes as easily as in twenty. This time should be cut accordingly in future experiments. A cautious approach toward raising the boil-up flux was followed initially (rightly so, as it turned out). However, by the time that testing was finished at $27 \%$ and $61 \%$ of the DWPF maximum boil-up flux (about 45 minutes), some mercury had undoubtedly been stripped, more nitrite had been destroyed, etc. A set of three pseudo-steady state foam heights at three different fluxes at twenty minutes each equated to 13,600 pounds of boiled water at DWPF scale, or close to $10 \%$ of the entire mass of water boiled off from the SRAT. The DWPF maximum boil-up flux needs to be attained more quickly. This is another reason to try and get the pseudo-steady state foam height data in about five minutes rather than twenty. Pseudo-steady state foam height measurements should be obtained at more wt. $\%$ total solids in order to better define any maxima that depend on flux and wt. \% total solids.

The tests intended to show the time dependence of processing on foaminess did not produce much conclusive data, i.e. the tests following dilution of the SRAT contents back to $\sim 21$ wt. \% total solids (e.g. IIT747-2 vs. IIT747-4) and the subsequent concentration back to 26 wt. \% (e.g. DC544-2 vs. DC544-5). Either the entire dilution/reconcentration portion of the experiment needs to be repeated several additional times in the same total elapsed time (possible with shorter foam tests) or this part of the testing should be abandoned. Another way to get at the time dependence of foam height would be to reflux the SRAT and do the same set of foam tests over and over. This might be useful early in the SRAT cycle boiling period when the processing conditions are changing the fastest.

\section{CONCLUSIONS AND RECOMMENDATIONS}

\section{Conclusions}

Italics denote the major conclusions given in the Executive Summary.

1. IIT747 antifoam was superior overall to Dow Corning 544 antifoam in controlling foam height and eliminating existing foams in these tests. The IIT747 antifoam appeared to be significantly superior to Dow Corning 544 antifoam when it mattered the most, which was at the onset of SRAT boiling following acid addition (SRAT Foam Test \#1 conditions). This situation coincided with the maximum liquid level in the full-scale SRAT and the corresponding smallest vapor space. The IIT747 antifoam appeared to be comparable to Dow Corning 544 antifoam at other times during both the SRAT and SME cycles. Furthermore, IIT747 antifoam was capable of collapsing foams that had already formed. Although the corresponding opportunities to test this did not arise during any of the Dow Corning 544 runs, it had 
been reported that Dow Corning 544 antifoam did not collapse foams formed in bench-scale work.

2. Fresh Dow Corning 544 antifoam was ineffective at controlling foaming when the SRAT was first brought to boiling at 65-107\% of the design basis DWPF boil-up flux (45 lb/hr/ft ${ }^{2}$ ). The GFPS SRAT would have foamed over into the SRAT condenser if the steam flux had been increased above $60 \%$ of the design basis. Fresh IIT747 antifoam, however, was effective at controlling foaming when the SRAT was first brought to boiling at up to $107 \%$ of the maximum DWPF boil-up flux. Just over four inches of foam were observed.

3. The two antifoams were effective at controlling foaming in the middle and latter parts of the SRAT cycle and were roughly comparable. Dynamically stable foams of 1-12 inches in height were observed at 27-107\% of the design basis DWPF boil-up flux. These foams collapsed when the steam supply was turned off.

4. Both antifoams were effective at controlling foaming during the SME cycle. Dynamically stable foams of only 1-4 inches in depth were observed at boil-up fluxes of 26-107\% of the design basis DWPF boil-up flux.

5. Adding IIT747 antifoam to a system already foaming uncontrollably eliminated the excess foam above the dynamically stable foam, i.e. it was an excellent defoamer.

6. There was some evidence that IIT747 antifoam was beginning to lose its effectiveness after about eight hours of SRAT cycle processing. It remained effective for ten hours at which point the process was shut down. IIT747 antifoam lost its effectiveness during another 15 hour period, much of which was not at elevated temperature. An "every twelve hours" addition strategy at 100 ppm may be inadequate in DWPF.

7. Both antifoams are blends of several compounds containing carbon, hydrogen, oxygen, and/or silicon. The impact of either antifoam per 100 ppm addition is an increase of about $0.0002 \%$ on the total silicon in the melter feed. Consequently, an antifoam switch is expected to have a negligible impact on glass chemistry.

8. The SRAT appears to become intrinsically less foamy as the chemical reactions go to completion.

9. Claims that Dow Corning 544 antifoam loses its effectiveness within an hour of addition were not supported by the findings in this study. There was ample evidence that simulant foaming could occur during either acid addition or boiling in the SRAT cycle and during boiling in the SME cycle. If the Dow Corning 544 antifoam had lost its effectiveness, it should have coincided with a large increase in foam height.

10. The SRAT conditions giving rise to maximum foaminess were high boil-up flux and low wt. \% total solids when Dow Corning 544 antifoam was used. When IIT747 
antifoam was used, however, the SRAT conditions giving rise to maximum foaminess were high boil-up flux and intermediate wt. \% total solids.

11. Gas generation was visibly correlated to foaming during acid addition. Evolved gases seemed to be enhancing foaming early in the SRAT cycle boiling period as well.

\section{Recommendations}

Italics denote the recommendations given in the Executive Summary.

1. DWPF should begin preparing to switch to IIT747 antifoam subject to completing item 2 below. A suitable supply source must be identified. This recommendation is conditional, since there are several unresolved issues at this time. The primary issue is the effective lifetime of the antifoam in actual DWPF processing.

2. Tests should be made to refine the addition strategy for a 100 ppm charge of IIT747 antifoam (suggest every eight hours if this testing can not be completed). Additional tests to determine the optimum antifoam addition concentration might reveal that less antifoam is needed later in processing, e.g. the SME cycle, then is needed during acid addition and initial SRAT cycle boiling. It is recommended that IIT747 antifoam either be added twice at $100 \mathrm{ppm}$ during SRAT acid addition or added at $150 \mathrm{ppm}$ rather than $100 \mathrm{ppm}$ prior to acid addition.

3. Tests should be performed with irradiated IIT747 antifoam to see it if retains its effectiveness. IIT747 antifoam could be used in the next shielded cell run.

4. Tests to determine the fate of IIT747 antifoam (or Dow Corning 544 antifoam) components during SRAT/SME processing should be performed. Antifoam components or their decomposition products could end up being recycled to the tank farm waste evaporator.

5. These tests were of the sludge-only flow sheet. The extrapolation of these findings to any form of coupled process operation in DWPF, per the outcome of Salt Disposition, is not recommended without further study. This work did not investigate the effect of organics, etc. on foam heights. It is not clear how the above findings would be applied if DWPF were to switch to a different operating flow sheet. The foaming issue should be revisited once a Salt Disposition Alternative decision has been made. New foam testing is recommended before any such switch is made.

6. These foam tests were empirical. Almost no data is available to support the assumption that a chemically similar, rheologically different simulant will foam the same as real waste. Rheological data could be obtained for Batch 1A, 1B, and 2 waste in the shielded cells and compared to corresponding simulant properties. Sufficient GFPS sample volume probably remains to check for a correlation between simulant slurry rheology and foaminess as measured during these tests. 


\section{REFERENCE SUMMARY}

Determine Effectiveness of IIT747 Antifoam for use in DWPF, December 7, 1998, TTR Number: HLW-DWPF-TTR-99-0012.

S. K. Bindal, Study of Three Phase Foam System, Masters Thesis, Illinois Institute of Technology, Chicago, IL, December 1999; Advisor - Dr. Darsh T. Wasan.

W. E. Daniel, $1 / 240^{\text {th }}$ Sludge Only Run: Acid and Frit Calculations, SRT-PTD-99-0039, July 13, 1999.

D. A. Edwards, H. Brenner, and D. T. Wasan, Interfacial Transport Processes and Rheology, Butterworth-Heinemann Series in Chemical Engineering, (C1991.

B. A. Halber, Foaming and Solids Carryover in the Full Scale SRAT/SME, DPST-88381, March 3, 1988.

M. S. Hay and N. E. Bibler, Characterization and Decant of Tank 42H Sludge Sample ESP-200, WSRC-RP-98-00406, Rev. 0, June 12, 1998.

N. D. Hutson, Foaming and Foam Detection in the DWPF Chemical Processing Cell, WSRC-TR-90-02120TL, May 1, 1990.

N. D. Hutson, Revision of Batch-1 Sludge Composition for Integrated Cold Runs in the Defense Waste Processing Facility (U), WSRC-TR-95-0079, February 16, 1995.

D. C. Koopman and D. P. Lambert, Hydrogen Generation and Foaming During Tests in the GFPS Simulating DWPF Operations with Tank 42 Sludge and CST (U), September 3, 1999, WSRC-TR-99-00302.

D. P. Lambert and D. C. Koopman, Comparison of Dow Corning 544 Antifoam to IIT747 Antifoam in the 1/240 SRAT, April 23, 1999, TTP: WSRC-RP-99-00205.

D. P. Lambert and C. S. Boley, Tank 42 Sludge-only Process Development for the Defense Waste Processing Facility (DWPF) (U), WSRC-RP-98-00149, Rev. 1, September 2, 1998.

D. P. Lambert, Craft Flowsheet and Antifoam Testing, WSRC-NB-97-247.

J. C. Marek, Final Report on Recommended CPC SRAT/SME Foam Program, SRTPTD-96-0076, Rev. 0, October 2, 1996.

S. M. Peters and J. C. Marek, Antifoam for DWPF Feed Preparation Processes, WSRCRP-89-968, September 27, 1989. 
Westinghouse Savannah River Company

Savannah River Technology Center
WSRC-TR-99-00377, Revision 0

ITS Activity No. ITS-99-0101

February 23, 2000

Z. H. Qureshi, Mixing and Sampling of Sludge-Frit-CST Slurries (U), September 1999, WSRC-TR-99-00309.

D. T. Wasan, Foaming and Antifoaming in Waste Processing, Final Report on Subcontract No. AB84968S, Illinois Institute of Technology, Chicago, IL, September 17, 1996. 


\section{ACKNOWLEDGEMENTS}

The author is grateful to both Dan Lambert and Russ Eibling for their guidance and insight into the DWPF Chemical Process Cell phenomena.

Appreciation is also extended to Frances Williams, John DuVall, Mary Moss, Vickie Williams, Tony Burckhalter, Sammie King, and Terri Snyder for doing an excellent job preparing for and carrying out the planned experiments. Their team approach toward work was very much appreciated. The long hours they worked to accomplish these experiments is to be commended.

This work would not have been possible without the efforts of Paul Burket, whose leadership was critical to taking the QVF supplied glassware and equipment and making it a fully functional, automated pilot plant that worked very well during these experiments. He was ably assisted by William Ryan and Nick Odom. Thanks to Vern Bush for his wiring of the electrical cabinet and thanks to Andy Foreman and Mike Armstrong for their assistance in the construction of the unit. Thanks to Erich Hansen for helping to find a replacement SRAT recirculation pump when the QVF pump failed.

Thanks to Paul Monson for his help in calibrating the GC and re-analyzing some data after the experiments were complete.

The continuing support of the technicians, engineers and management of the Thermal Fluids Engineering Lab was greatly appreciated. Special thanks to Mark Fowley for leading the PHR process and Tim Steeper and Dan Burns for their engineering insight and support. Thanks to Jerry Corbett for planning the reconfiguration of the unit to allow better use of the space and allow better use of the unit. Thanks to Susan Hatcher for coordinating the various tasks in the Thermal Fluids Lab. 


\section{Distribution:}

L. M. Papouchado, 773-A

E. W. Holtzscheiter, 773-A

L. F. Landon, 704-1T

S. L. Marra, 704-T

C. T. Randall, 773-42A

D. A. Crowley, 773-43A

R. H. Spires, 773-A

D. B. Burns, 786-5A

C. M. Jantzen, 773-A

D. C. Koopman, 704-1T

D. P. Lambert, 704-1T

R. E. Eibling, 704-1T

W. E. Daniel, 704-1T

J. R. Harbour, 773-43A

N. E. Bibler, 773-A

T. L. Fellinger, 773-A

D. F. Bickford, 773-43A

T. K. Snyder, 704-T

M. F. Williams, 704-1T

STI, 703-43A (4) 